\title{
PREVENCIÓN Y GARANTÍAS: CONFLICTO Y SÍNTESIS
}

\author{
Rafael Alcácer Guirao \\ Universidad Complutense de Madrid
}

"Cada persona posee una inviolabilidad fundada en la justicia que incluso el bienestar de la sociedad como un todo no puede atropellar"

Rawls, Teoría de la justicia.

\section{Introducción al conflicto: perspectiva penal, ética y política*}

\section{El dilema del derecho penal}

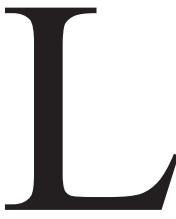

o que caracteriza a la institución social de la pena y dota a la discusión acerca de su justificación de hondas repercusiones éticas es su carácter de arma de doble filo con respecto a la libertad individual ${ }^{1}$ : la pena se legitima en función de su labor de protección de la libertad de los ciudadanos, pero para ello se agrede al mismo tiempo, con su imposición, la libertad de los ciudadanos. Ese dilema genera además una relación de tensión: toda protección de la libertad conlleva asimismo una recíproca limitación de la libertad, por lo que a mayor protección preventiva mayor detrimento de la libertad de todos.

Dicha tensión es la que en la discusión político-criminal acerca de la legitimidad del Derecho penal se plasma en el binomio dialéctico prevención/ garantías, existiendo un permanente conflicto entre ambas orientaciones: si bien a mayor prevención mayor detrimento de las garantías, el conflicto surge también desde la perspectiva inversa: a mayor maximización de las garantías menor funcionalidad preventiva de la pena en su cometido de

*Abreviaturas empleadas: ADPCP: Anuario de Derecho Penal y Ciencias Penales. AFD: Anuario de Filosofia del Derecho. ARSP: Archiv für Rechts- und Sozialphilosophie. AT: Allgemeiner Teil (Parte General). CPC: Cuadernos de politica criminal. FS: Festschrift GA: Goldtdammer's Archiv für Strafrecht. JA: Juristische Arbeitsblätter. Jura: Juristische Ausbildung. JZ: Juristenzeitung. KrimJ: Kriminolosgisches Journal.NDP: Nueva Doctrina Penal (Argentina). NStZ: Neue Zeitschrift für Strafrecht. PJ: Poder Judicial. ZRP: Zeitschrift für Rechtspolitik. ZStW: Zeitschrift für die gesamte Strafrechtswissenschaft.

${ }^{1}$ En similar sentido, WOLF, Verhütung oder Vegeltung? Einführung in ethische Straftheorien, 1992, p. 129 
protección de esferas de libertad, dado que las garantías individuales operan como espacios de libertad limitadores de la intervención penal.

\section{Consecuencias y principios}

Para intentar siquiera desentrañar los hilos de ese dilema es preciso, en primer lugar, que nos detengamos en la vertiente metáetica de ambas direcciones. A muy grandes rasgos, puede afirmarse que el binomio prevención / garantías se corresponde con dos tradiciones éticas opuestas, que hasta la actualidad han venido enfrentándose mutuamente. La orientación preventiva, de una parte, se enmarca en la tradición utilitarista, que aspira a maximizar el bienestar de la colectividad, pudiendo menoscabar, entonces, en aras de dicho objetivo, la libertad del individuo concreto; la orientación garantística, de otra, sigue la senda de la tradición kantiana, que considera prioritaria la libertad individual frente a cualquier aspiración al bien común, proscribiendo toda funcionalización de dicha libertad en aras de fines sociales ${ }^{2}$.

Expresado en términos metaéticos: la prevención partiría de una racionalidad teleológica, cuyo único criterio de corrección sería la consecución de los fines asignados, y la atención a las garantías de una racionalidad deontológica, cuyo criterio de corrección parte de la adecuación de la acción individual o social a determinados valores o principios, con independencia respecto a la satisfacción de resultados ${ }^{3}$ y que se incardinaría, entonces, como un contrapeso limitador a la racionalidad instrumental ${ }^{4}$, sólo dentro de cuyos márgenes podrá hacerse efectiva la satisfacción de fines ${ }^{5}$.

La tensión entre ambos criterios viene dada porque la opción por uno sólo de ambos y la prescindencia, con ello, del opuesto, llevaría a la irraciona-

\footnotetext{
${ }^{2}$ Si bien en otros términos, opone asimismo ambas tradiciones SILVA SÁNCHEZ, Aproximación al Derecho penal contemporáneo, 1992, citando a Nino.

${ }^{3}$ Ambos criterios se encuentran ya en Max WEBER Soziologische Grundbegriffe, 1984 (4 $4^{\mathrm{a}}$ ed.), pp. 44 ss., bajo los términos de Zweckrationalität y Wertrationalität, respectivamente. Vid. asimismo MAIHOFER, Die gesellschaftliche Funktion des Rechts, en Die Funktion des Rechts in der modernen Gesellschaft, Jahrbuch für Rechstsoziologie und Rechtstheorie, 1, 1970 , pp p. 27 ss. Dada la oposición correlativa entre consecuencias y principios, algún autor ha caracterizado dicha dualidad bajo la denominación de consecuencialismo (término clásico en la teoría ética) y principialismo (neologismo): Cfr. SILVA SÁNCHEZ, Política criminal en la dogmática: algunas cuestiones sobre su contenido y límites, en: Silva Sánchez (editor), Politica Criminal y nuevo Derecho penal, 1997, pp. 19-20. Sobre la caracterización del utilitarismo como una teoría consecuencialista, cfr. PETIT, El consecuencialismo, en Compendio de ética, Singer (edit.), Madrid, 1995, pp. 323 ss.

${ }^{4}$ Así, VOSS, Symbolische Gesetzgebung, Fragen zur Rationalität von Strafgesetzgebungsakten 1989, p. 19, desde una interpretación de Weber.

${ }^{5}$ Es a partir de estos presupuestos como BURKHARDT, Das Zweckmoment im Schuldbegriff, GA 1976, p. 324, puede distinguir entre un concepto teleológico y uno deontológico de culpabilidad.
} 
lidad, es decir, a la ilegitimidad: un modelo deontológico puro de acción social se presentaría como irracional desde la racionalidad instrumental, dada su desatención de los resultados. El detrimento de la libertad del ciudadano con la imposición de la pena sería, entonces, gratuito y, por ello, ilegítimo, dado que vulneraría la exigencia de utilidad y necesidad del castigo. Pero un modelo teleológico puro sería, en cambio, irracional desde la perspectiva deontológica, dada la ausencia de límites a esa persecución de resultados. El fin justificaría los medios y se estaría, en términos kantianos, identificando a la persona con el Derecho de cosas.

Por ello, la única vía de legitimación pasaría por llegar a un equilibrio razonable entre ambos criterios, de modo que la actuación del Derecho venga determinada por una ponderación, en diferentes posibilidades graduales, de ambas formas de racionalidad. Tal es, de hecho, el consenso actualmente existente en la discusión políticocriminal: que ninguna de ambas direcciones puede erigirse en exclusivo factor de legitimación del Derecho penal, desatendiendo a su contrario, por cuanto ese desequilibrio extremo llevaría, a la postre, a frustrar el cometido de protección de la libertad del Derecho penal, ya por anular la capacidad preventiva, ya por anular las limitaciones garantísticas. El problema pasa, entonces, por intentar hallar una síntesis entre prevención y garantías ${ }^{6}$.

Conflicto y síntesis: el conflicto como realidad y la síntesis como aspiración. Tales son los polos de la polémica. Así, veremos que la discusión doctrinal puede dividirse entre quienes han optado por la solución del conflicto y quienes han intentado llegar a una solución de síntesis. Pero antes de ello situemos la polémica también en otro plano de discusión.

\section{El problema de la estabilidad social: liberalismo y comunitarismo}

El Derecho penal no es un fin en sí mismo, sino un instrumento al servicio de determinados fines sociales. Más allá de las diferentes posibilidades de concreción, en un plano genérico el Derecho penal sirve, al igual que el Estado, al fin de la estabilidad social: mantener inalteradas determinadas normas de convivencia, evitando el bellum omnium contra omnes. Por ello,

\footnotetext{
${ }^{6}$ Así, entre otros muchos, HAFFKE, Tiefenpsychologie und Generalprävention. Eine strafrechtstheoretische Untersuchung, 1976, p. 69; NAUCKE, Generalprävention und Grundrechte der Person, en Hauptprobleme der Generalprävention, Hassemer/Lüderssen/Naucke (edit.), 1979, pp. 7 ss. (pp. 23 ss. y passim) ; KUNZ, Prävention und Gerechte Zurechnung, ZStW 98 (1986) , p. 828 ; PÉREZ MANZANO, Culpabilidad y prevención: Las teorias de la prevención general positiva en la fundamentación de la imputación subjetiva y de la pena, 1990, p. 221; HÖRNLE/v. HIRSCH, Positive Generalprävention und Tadel, GA 1995, p. 265. Una lúcida presentación y desarrollo del problema desde esa caracterización dialéctica expuesta en el texto ofrece SILVA SÁNCHEZ, Aproximación (nota 2), pp. 202 ss.
} 
la discusión acerca de la legitimidad del Derecho penal estará íntimamente vinculada al modelo ideológico de Estado de que se parte, por lo que en la polémica entre prevención y garantías deberán tenerse muy presentes las implicaciones ideológicas que sustentan las bases teóricas de la misma? Como ha afirmado Müller-Dietz, "ocuparse del fundamento jurídico y fines de la pena criminal no es suficiente... Desde una perspectiva teórica se trata también de la comprensión del Estado que yace tras la determinación de las funciones del Derecho penal, y con ello, al mismo tiempo, de la relación del individuo en y con el Estado".

Tal ha sido el gran interrogante que desde los orígenes de la filosofía política ha quitado el sueño a los pensadores: ¿cómo es posible la estabilidad social? Interrogante que incide directamente en nuestra discusión, por cuanto la pena aparece como uno de los medios por excelencia para alcanzar esa estabilidad social, y atiende, por ello, a la discusión esencial acerca de cómo establecer de las relaciones entre Estado e individuo; en términos más habituales para nosotros, la cuestión sería: ¿hasta qué punto es legítimo, en aras de fomentar la estabilidad social, servirse de derechos individuales de los ciudadanos? Los polos del conflicto son, en realidad, los mismos: aseguramiento de fines preventivos versus respeto a garantías individuales; o bien: fomento del bien común versus respeto a los derechos individuales.

Entramos de lleno, así, en el ámbito de la filosofía política. Si desde un plano ético habíamos plasmado la oposición entre dos tradiciones: la utilitarista y la kantiana, en el ámbito en el que nos hemos introducido ahora dicha oposición se transmuta en la existente entre dos líneas de pensamiento político: comunitarismo y liberalismo ${ }^{9}$.

${ }^{7}$ MIR PUIG, Función de la pena y teoría del delito en el Estado social y democrático de Derecho, en: Mir Puig, El Derecho penal en el Estado Social y Democrático de Derecho, 1994, p. 29: "La discusión sólo podrá discurrir sobre bases racionales si no se ocultan las premisas políticas de las que depende".

${ }^{8}$ MÜLLER-DIETZ, Integrationsprävention und Strafrecht, Jescheck- Festschrift, 1985, p. 812. La innegable dependencia de la concepción del Derecho penal de la propia comprensión del Estado que se mantenga es resaltada asimismo, entre otros, por MIR PUIG, Función de la pena (nota 7), p. 29, quien habla de la "vinculación axiológica...entre función de la pena y función del Estado”; OCTAVIO DE TOLEDO, Sobre el concepto del Derecho penal, 1981, p. 197 y passim; FEIJOO SÁNCHEZ, El injusto penal y su prevención ante el nuevo Código Penal de 1995, 1997, p. 28: "La concepción del Estado condiciona el papel del Derecho penal".

${ }^{9}$ Sería imposible dedicar aquí el suficiente espacio para una exposición detallada de lo que separa a ambas líneas de pensamiento, por lo que el lector no versado en estos temas tendrá que conformarse con las breves indicaciones que se harán a continuación. Para un amplio análisis de dicha discusión, y sus relaciones con la legitimación del Derecho penal, me permito remitir a ALCÁCER GUIRAO, Los fines del Derecho penal. Liberalismo y comunitarismo en la justificación de la pena, Buenos Aires, 2001, passim. 
El desencuentro entre ambas doctrinas es determinante para la discusión que nos ocupa. Lo que, por encima de todo, caracteriza al liberalismo es la prioridad dada a los derechos individuales frente a todo tipo de satisfacción de intereses o fines supraindividuales. Estos Derechos se erigen como una "envoltura de protección" frente a los intereses colectivos y la acción coercitiva del Estado que, a modo de un derecho de defensa, garantiza que principios como el de la dignidad humana o el de autonomía moral no puedan ser supeditados o funcionalizados para la persecución del bien común ${ }^{10}$. Desde esta perspectiva, el liberalismo -siguiendo la estela de la tradición kantiana- acogería esa racionalidad deontológica que auspiciaría la atención a las garantías individuales. Frente a esa doctrina, el comunitarismo parte del presupuesto contrario: el prius axiológico no radica en la libertad individual, sino en el mantenimiento de los vínculos valorativos que cohesionan y dan su identidad a la comunidad, en aras de su estabilidad y del bien de la colectividad. Por ello, desde esta orientación colectivista los derechos de las personas pueden en ocasiones verse vulnerados legítimamente en aras del mayor bien de la identidad común ${ }^{11}$. Dicho presupuesto aproxima induda-

\footnotetext{
${ }^{10}$ Cfr. RAWLS, Teoría de la justicia, 1995 (reimpresión), pp. 19-20: "Cada persona posee una inviolabilidad fundada en la justicia que incluso el bienestar de la sociedad como un todo no puede atropellar". En este sentido, cfr., por ejemplo, FORST, Kontexte der Gerechtigkeit, 1996, p. 51; HABERMAS, Facticidad y validez. Sobre el Derecho y el Estado democrático de derecho en términos de teoría del discurso, 1998, pp. 178, 142, 323 (citando a Böckenförde: "En esos derechos fundamentales interpretados como derechos de defensa, no es la libertad del uno la que es tenida por compatible con la del otro en general conforme a una ley general de la libertad, sino la libertad del ciudadano individual con la del Estado"); el mismo, "Razonable" versus "verdadero" o la moral de las concepciones del mundo, en Habermas/Rawls: Debate sobre el liberalismo politico, 1998, p. 179: "El liberalismo político o de Estado de Derecho parte de la intuición de que el individuo y su forma de vida individual tienen que ser protegidos frente a las intrusiones del poder del Estado". En idéntico sentido, ya Bentham estimaba que "la libertad personal es la seguridad contra cierto tipo de injerencias contra la persona. Y la llamada libertad política es otra rama de la segu ridad, la seguridad contra la injusticia de los detentadores del poder público" (Citado por MORESO, La teoría del Derecho en Bentham, 1992, p. 327.) Vid. también ROXIN, Sinn und Grenzen staatlicher Strafe, en: Roxin, Strafrechtliche Grundlagenprobleme, 1973, p. 21, quien habla de un derecho de defensa frente al poder estatal exigido desde el principio de culpabilidad e inferido desde el principio de la dignidad humana.

${ }^{11}$ Cfr., en esta línea, TAYLOR, Aneinander vorbei: Die Debatte zwischen Liberalismus und Kommunitarismus, en Honeth (edit.), Kommunitarismus. Eine Debatte über die moralischen Grundlagen moderner Gesellschaften, 1993, pp. 103, p. 130, ejemplificándolo con la defensa de la tradición cultural francesa de la comunidad de Quebec; MACINTYRE, Ist Patriotismus eine Tugend?, en Honeth (edit.), Kommunitarismus (ob. cit.), p. 94 . En este sentido, afirma GUTMANN, "Keepin 'em down on the farm after they've seen Paree”: Aporien des Kommunitaristischen Rechtsbegriffs, ARSP 1997, p. 59, que en el comunitarismo “el 'valor' social de las personas como miembros de la comunidad se determina en función de su disposición a la realización de...ese bien común".
} 
blemente el comunitarismo al criterio consecuencialista del utilitarismo ${ }^{12}$, en cuanto que lo relevante es la satisfacción de fines sociales -el bienestar del mayor número, la estabilización del colectivo-, aun en detrimento de intereses del individuo en particular. Sabido es, en este sentido, que el utilitarismo ha tenido que enfrentarse siempre a objeciones relativas a la injusticia en la distribución de bienes, ya que la maximización del bienestar para el mayor número desatiende la justicia en el reparto equitativo entre personas ${ }^{13}$. En este sentido, las críticas que Rawls -eminente representante del liberalismo de raíz kantiana- dirige a la doctrina utilitarista parten precisamente del hecho de que el utilitarismo adopta "para la sociedad, como un todo, el principio de elección racional del individuo"14, por lo que "el utilitarismo no es individualista" 15 , sino que, por el contrario, como afirma Nino, poniéndolo también en relación con el substrato del comunitarismo, parte "de un carácter agregativo y, por ende, holista" $"$.

Así, frente a la exclusiva tendencia preventiva del comunitarismo, y frente a la maximización a cualquier precio de la estabilidad social, una perspectiva liberal en este ámbito se caracterizaría por el acuerdo intersubjetivo, en base al modelo del contrato social ${ }^{17}$, acerca del establecimiento de principios limitadores que sirvieran como una esfera de protección frente a la inercia preventiva estatal, basada en intereses colectivos, del ius puniendi, sin por ello abandonar la pretensión preventiva de protección de los intereses personales a través de la pena, por cuanto ese cometido también aspira, a la postre, a garantizar esferas de libertad individual. Tal será, en efecto,

\footnotetext{
${ }^{12}$ Cfr., por ejemplo, BILBENY, Política sin Estado, 1998, pp. 81-82, destacando que en los planteamientos autoritarios de Hegel el fin justificará los medios. Vid. también NINO, Ética y derechos humanos, 1989, p. 212.

${ }^{13}$ Críticas de esta índole sobre el utilitarismo pueden encontrarse en NINO, Introducción al análisis del Derecho, 1991 (4a edición), p. 400; WILLIAMS, der Begriff der Moral. Eine Einführung in die Ethik, 1994, p. 102; FRANKENA, Analytische Ethik. Eine Einführung, 1994

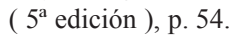

${ }^{14}$ RAWLS, Teoría de la justicia (nota 10), p. 45.

${ }^{15}$ RAWLS, Teoría de la justicia (nota 10), p. 48.

${ }^{16}$ NINO, Ética y derechos humanos (nota 12), p. 212.

${ }^{17}$ Sobre el contrato social, en sus perfiles actuales, cfr. RAWLS, Teoría de la justicia (nota 10), pp. 28 ss., y passim. A diferencia de autores clásicos como Locke, Kant o Rousseau, Rawls no se sirve del contrato social para fundar el Estado, sino para establecer, a través de un acuerdo intersubjetivo basado en la racionalidad de las partes y realizado en términos de igualdad, determinados principios de justicia, los cuales, en cualquier caso, servirán para la legitimación de las instituciones públicas básicas. Sobre dicha concepción y aplicación de la figura del contrato social, cfr. también NINO, Introducción (nota 13), pp. 409-410; KOLLER, Theorien des Sozialkontrakts als Rechtfertigungsmodelle politischer Institutionen, en O. WeinbergerFestschrift, 1984, pp. 241 y 243 ss.
} 
la postura que aquí se acogerá, intentando llegar a una cierta convivencia pacífica de ambos polos en virtud de los postulados del liberalismo.

Antes de ello, expondré las distintas concepciones que acerca de dicha tensión se han dado en la discusión científica. Para ello centraremos nuestra atención en el principio de culpabilidad, en cuanto criterio para la determinación del grado de distribución de la pena impuesta, momento en el cual el menoscabo de la libertad de ciudadano por la pena se hace más incisivo ${ }^{18}$. Desde esta perspectiva, el conflicto tantas veces citado puede designarse mediante el binomio prevención/retribución, en tanto que la idea de la retribución, siendo ilegítima como fin de la pena, por desatender radicalmente el principio de la utilidad o necesidad de pena ${ }^{19}$, acoge en su seno esa exigencia garantística de aplicación de la pena en virtud de los principios de culpabilidad y proporcionalidad ${ }^{20}$ y el consiguiente rechazo a toda instrumentalización del ciudadano ${ }^{21}$. Tal sería, en palabras de Jellinek, el "núcleo de verdad" de las tesis retributivas ${ }^{22}$, en cuya virtud ha podido afirmarse que "los principios del retribucionismo pueden representar una valiosa restricción de la poderosa razón del bien social frente al individuo"23.

${ }^{18} \mathrm{Y}$, por esa razón, es en su discusión done más se ha hecho incidencia en el dilema entre prevención y garantías. Cfr., entre muchos, JAKOBS, El principio de culpabilidad, en: Jakobs, Estudios de Derecho penal, 1997, p. 366: "sin respetar el principio de culpabilidad, la pena es ilegítima; pero si el principio de culpabilidad limita considerablemente la utilización de medios socialmente funcionales, esto es, si tiene un significado y no es un concepto vacío, entonces existe el peligro de que la pena sea inadecuada para la consecución de sus fines y sea ilegítima por esa otra razón". En similar sentido, ya, el mismo, Culpabilidad y prevención, en: Jakobs, Estudios de Derecho penal, 1997, p. 75.

${ }^{19}$ Sobre el principio de utilidad, vid. ALCÁCER GUIRAO, Los fines del Derecho penal (nota 9), pp. 34-35.

${ }^{20}$ Así, BAURMANN, Strafe im Rechtstaat, en: Baurmann/Kliemt (editores), Die moderne Gesellschaft im Rechtstaat, 1991, p. 122-123.

${ }^{21}$ En este sentido, entre otros (vid. nota siguiente), SILVA SÁNCHEZ, Aproximación (nota 2), p. 306-307, considerándolo "la aportación práctica esencial del pensamiento retribucionista clásico"

22 JELLINEK, Die sozialethische Bedeutung von Recht, Unrecht und Strafe, 1967 (Reed. del original de 1878), p. 105. Sobre las citadas bondades de la idea retributiva vid. también HART, Prolegomenon to the principles of punishment, en: Hart, Punishment and Responsibility. 1968, p. 12; OCTAVIO DE TOLEDO, Sobre el concepto (nota 8), p. 204; HASSEMER, Fines de la pena en el Derecho penal de orientación científico-social, en: Mir Puig (editor), Derecho penal y ciencias sociales, 1982, p. 125; BETEGÓN, La justificación del castigo, 1992, pp. 330 ss.

${ }^{23}$ BETEGÓN, La justificación del castigo (nota 22), p. 332 


\section{Soluciones de conflicto y soluciones de síntesis}

\section{Soluciones de síntesis: la culpabilidad se fundamenta en la prevención}

a) Exposición

En primer lugar se valorarán las teorías que, a la hora de legitimar la pena, operan exclusivamente desde el criterio consecuencialista de la prevención efectiva, prescindiendo del establecimiento vinculante de garantías individuales como la culpabilidad o la proporcionalidad, por entender que es en el seno de la propia lógica preventiva donde pueden encontrarse límites a la inercia preventiva estatal. Son las teorías que, negando dicha situación de conflicto, establecen una solución de síntesis a la relación entre la prevención y las garantías.

Como se acaba de afirmar, lo que caracteriza a dichas soluciones de síntesis es la presunción de que no es preciso establecer límites externos a la propia lógica preventiva, puesto que ésta conlleva en sí misma su propia autolimitación, y consigue, por tanto, evitar situaciones como la punición de inimputables o en general la tendencia a la agravación del grado de la pena, situaciones que clásicamente han venido criticándose de la racionalidad teleológica exclusivamente maximizadora de la prevención. Dentro de este grupo, pueden distinguirse a su vez dos concepciones, respondiendo cada una a las dos formas de prevención general.

En primer lugar, la solución de síntesis se defiende desde la prevención general negativa. Los defensores de esta postura sostienen que la prevención no ha de llevar a la punición de inimputables, puesto que la utilización de la pena sobre esa clase de personas no es preventivamente necesaria. Desde la amenaza de pena, porque no son motivables por la misma; pero tampoco la imposición de una pena a un inimputable tendría efectos de intimidación sobre futuros delincuentes, y ello, se afirma, porque entre los individuos imputables se da un "proceso de identificación" que permite diferenciar efectos preventivos con respecto a los inimputables. Se sostiene, así, que "la impunidad del loco en nada relaja la eficacia inhibitoria de la pena frente a los 'imputables'; éstos no se identifican con aquél, se saben distintos y saben también, por consiguiente, que a ellos sí que les van a castigar si hacen lo mismo que el enajenado delincuente"24.

${ }^{24}$ GIMBERNAT, El sistema de Derecho Penal en la actualidad, en: Gimbernat: Estudios de Derecho Penal, 1990 ( $3^{\text {a }}$ edición), pp. 176 -177; en igual sentido, el mismo autor, en ¿Tiene un futuro la dogmática jurídico-penal?, en: Estudios (op. cit.), p.157. Le sigue LUZÓN, Medición de la pena y sustitutivos penales. 1979, pp. 38 ss., 46 ss. ; el mismo, Prevención general y psicoanálisis, en: Mir Puig (editor), Derecho penal y ciencias sociales, 1982, pp. 144 ss. 
La solución de síntesis es defendida también desde la prevención general positiva. La forma de solucionar la tensión entre prevención y retribución de esta teoría presenta una especial particularidad. A diferencia de la concepción anterior, que prescinde de cualquier referencia a principios subyacentes a la retribución, esta forma preventiva atribuida a la pena extrae la veta utilitarista precisamente del propio pensamiento retributivo. La prevención general positiva hace suyo un hecho que ya venía evidenciándose desde hacía años en la concepción absoluta de la pena, consistente en la paradójica "persecución de fines y negación de fines" 25 : en que tras la aparente desvinculación de todo fin latía cierto telos vinculado a la influencia de la pena en el colectivo social respecto a la vigencia del Derecho y a necesidades de estabilidad social, mucho más mundano y contingente que la pretensión metafísica de justicia ${ }^{26}$. El recurso a la funcionalidad del aspecto retributivo de que se nutre la prevención general positiva implica la asunción de una relación de reciprocidad entre utilidad y justicia: no sólo la pena útil es la pena justa -en cuanto legítima-, sino que también sólo una pena justa será una pena útil a esos fines preventivos, por cuanto sólo entonces será aceptada por la ciudadanía.

La prevención general positiva no busca producir efectos preventivos a través de la intimidación, sino que tal prevención se busca mediatamente, a través de la pena impuesta, por medio de la estabilización de la conciencia jurídica colectiva y el restablecimiento del equilibrio psico-social alterado

${ }^{25}$ HASSEMER, Fines de la pena (nota 22), p. 126.

${ }^{26}$ La proximidad entre la retribución y la prevención general positiva ha sido puesta de manifiesto ampliamente por la doctrina. Por un lado, se llega a dudar si alguna vez fue defendida la retribución como "desvinculada de todo fin". Así, HASSEMER, Fines de la pena (nota 22), p. 126; FROMMEL, Umrisse einer liberal-rechtsstaatlichen Normverdeutlichung durch Strafrecht, Schüler-Springorum-Festschrift, 1993, p. 271: "La pena en el modelo clásico de retribución es...protección de la norma. La teoría era y es preventiva: su finalidad es el mantenimiento de la autoridad de la ley lesionada". (Cursivas en el original). Cfr., además, LUZÓN, Medición (nota 24), p. 36, afirmando que la prevención general positiva no es otra cosa que retribución teñida de tintes psicológico-sociales. Cfr. también KAUFMANN, Arthur, Über die gerechte Strafe, Hilde Kaufmann-Festschrift, 1987, p. 429; PÉREZ MANZANO, Culpabilidad y prevención (nota 6), p. 29; PAPAGEORGIOU, K.A., Schaden und Strafe, 1994, pp. 32 ss; SILVA SÁNCHEZ, Aproximación (nota 2), p. 227; MÜLLER-TUCKFELD, Integrationsprävention. Studien zu einer Theorie der gesellschaftlichen Funktion des Strafrechts, 1997, p. 29: "El fin de la pena aparentemente carente de fines es el restablecimiento de la autoridad del Derecho a costa del delincuente a través de la pena ejemplar impuesta en su caso". Asimismo, las teorías que, partiendo del funcionalismo de Durkheim, centradas en el fin de integración por medio de la satisfacción de instintos colectivos de venganza asumen dicho fin de la pena como "necesidad social de retribución”. Cfr., por ejemplo, STRENG, Schuld, Vergeltung, Prävention, ZStW 92 (1980), p. 649; ACHENBACH, Imputación individual, responsabilidad, culpabilidad, en: Schünemann (compilador), El Sistema moderno del Derecho penal: cuestiones fundamentales , 1991, p. 140. 
por el delito ${ }^{27}$. Así contemplada, la tesis de partida es que sólo la pena ajustada a la culpabilidad puede ser aceptada socialmente y cumplir su misión de mantener la confianza y ejercer la fidelidad en el ordenamiento jurídico. En consecuencia, a juicio de sus defensores, la prevención general positiva incorpora en sus fines su propia limitación y consigue evitar la tendencia al terror penal propia de la prevención de intimidación, ya que la punición de inimputables o la imposición de penas que superaran lo ajustado a la culpabilidad irían en detrimento de la aceptación del Derecho como orden justo por la comunidad ${ }^{28}$.

\section{b) Valoración crítica a las soluciones de sintesis}

Ciertamente, a primera vista las soluciones de síntesis se presentan más convincentes y operativas, en tanto en cuanto permiten atender a las exigencias garantísticas sin abandonar la fundamentación preventiva que debe legitimar toda la labor de la institución penal, evitando además las a veces irreductibles antinomias que produce el enfrentamiento de principios opuestos propio de las soluciones de conflicto. Sin embargo, es la pretendida armonía con que se afirma que puede resolverse el permanente binomio utilitarismo/justicia la que genera dudas respecto de la viabilidad de tal propuesta $^{29}$.

${ }^{27}$ Sobre las teorías de la prevención general positiva, y sus diferentes versiones, cfr. ALCÁCER GUIRAO, Los fines del Derecho penal (nota 9), pp. 49 ss.

${ }^{28}$ Cfr. ROXIN, Zur jüngsten Discussion über Schuld, Prävention und Verantwortlichkeit, Bockelmann-Festschrift, 1979, p. 305; MÜLLER-DIETZ, Jescheck-Festschrift (nota 8), 1985, pp. 818 ss; ZIPF, Die Integrationsprävention (positive Generalprävention), Pallin-Festschrift, pp. 308 ss.; ACHENBACH, Imputación individual (nota 26), pp. 140; STRENG, ZStW 101 (1989), p. 292; el mismo, Strafrechtliche Sanktionen. Grundlagen und Anwendung, 1991 pp. 11-12; Vid., además, aunque con importantes diferencias, que después destacaremos, WOLFF, Das neuere Verständnis von Generalprävention und seine Tauglichkeit für eine Antwort auf Kriminalität, ZStW 97 (1985), p. 800; KUNZ, Prävention und gerechte Zurechnung, ZStW 98 (1986), p. 832; HÖRNLE/von HIRSCH, Positive Generalprävention und Tadel, GA 1995, p. 264; BAURMANN, Vorüberlegungen zu einer empirischen Theorie der positiven Generalprävention, GA 1994, pp. 379 ss.; PÉREZ MANZANO, Culpabilidad (nota 6), pp. 134; MIR PUIG, Función fundamentadora y función limitadora de la prevención general positiva, en: Mir Puig, El Derecho penal en el Estado Social y Democrático de Derecho, 1994, pp. 129 ss., quien plantea la prevención general positiva atendiendo exclusivamente a sus límites frente a los excesos inherentes a la intimidación, rechazando, en cambio, las concepciones que pretenden servirse de dicho fin de la pena como fundamento y legitimación de la pena y del Derecho penal. Vid. infra sobre esta posición.

${ }^{29}$ Afirma en este sentido BURKHARDT, GA 1976, p. 336, que, habiendo sido tradicionalmente el principio de culpabilidad un criterio restrictivo, las concepciones teleológicas de la culpabilidad - las que pretenden derivarla de la propia lógica preventiva - se presentan, en cierta medida, como paradójicas. 
Si bien es en la actualidad, a partir del abandono de fundamentaciones absolutas de la pena y de la acentuación de la pena como instrumento social, cuando más generalizadas aparecen estas tesis, la pretensión de derivar principios limitadores de la lógica preventiva es tan antigua como la propia doctrina utilitarista. Así, ya Bentham se había esforzado por extraer límites a la función preventiva de intimidación sin abandonar el seno de su doctrina ética utilitarista, afirmando que la prevención presupone un principio de culpabilidad, puesto que el efecto intimidatorio sólo puede producirse sobre personas capaces de comprender el sentido de la amenaza y actuar en consecuencia al mismo ${ }^{30}$. Pero la ingenuidad de que pecaba esta postura la convertía en objeto de fáciles críticas. Así, Hart calificó los argumentos de este autor como un "espectacular non sequitur": todo lo que demuestra con sus afirmaciones es que la amenaza de pena no tendría efecto sobre los inimputables, pero nada dice respecto del hecho de que la punición de un inimputable no vaya a tener efectos preventivos frente a eventuales terceros imputables, lo cual es, afirma el jurista anglosajón, perfectamente factible ${ }^{31}$.

No obstante, desde las filas de la prevención general negativa se ha dado respuesta a esa cuestión: es, como ha sido destacado, ese proceso de identificación entre imputables lo que permite separar cognitivamente efectos preventivos entre ambos grupos de individuos. ¿Pero hasta qué punto resulta convincente tal afirmación? Podría, prima facie, ser plausible que los individuos accesibles al mandato normativo no deducirían una relativización de la amenaza dirigida a ellos si quedara impune un oligofrénico profundo, pero tal presunción pierde fuerza si nos referimos a otro tipo de inimputables como menores de edad, o si la impunidad es consecuencia de un error (invencible) de prohibición ${ }^{32}$. Una teoría que pretenda fundar un límite firme, es decir, no contingente, a la punición indiscriminada de inimputables debe estar en disposición de demostrar que dicho límite puede justificarse en todos los casos, y no sólo generalmente. Además, para poder ofrecer un límite seguro, el razonamiento utilitarista sobre el fundamento de la limitación debe poder argumentarse también en sentido positivo: desde esta postura todo

\footnotetext{
${ }^{30}$ Sobre la postura de Bentham, cfr. BAURMANN, Folgenorientierung und subjektive Verantwortlichkeit, 1981, pp. 19 ss.

${ }^{31}$ HART, Prolegomenon (nota 22), p. 19. Vid. también BURKHARDT, GA 1976, pp. 336337; KIM, Zur Fragwürdigkeit und Notwendigkeit des strafrechtlichen Schuldprinzips. Ein Versuch zur Rekonstruktion der jüngsten diskussion zu "Schuld und Prävention", 1987, p. 107, citando a Burkhardt.

${ }^{32}$ Gimbernat extiende la idea de la identificación también respecto a los sujetos en error de prohibición. Cfr. El sistema (nota 24), pp. 177-178. Críticas similares se encuentran en PÉREZ MANZANO, Culpabilidad (nota 6), pp. 149 ss.
} 
lo que se afirma es que "las prohibiciones penales no pierden nada de su vigor inhibitorio porque los 'inimputables' queden exentos de responsabilidad criminal" ${ }^{\prime 33}$, pero nada dice respecto de que la punición a un inimputable no haya de aumentar dicho vigor inhibitorio sobre los futuros delincuentes imputables. La lógica del imputable, según esa tesis, sería: "al inimputable no le imponen la pena por la realización de una acción contraria a la norma, pero como yo no soy como él, a mí sí me la impondrán”, pero, imponiendo la pena también a los inimputables, ese proceso de identificación llevaría al siguiente razonamiento: "si a un inimputable le imponen una pena qué no harán conmigo, que no soy como él". Es decir, la punición de inimputables aumentaría la efectividad preventiva, y una teoría utilitarista que fundamente la pena exclusivamente en dicha lógica tiene que partir siempre de la efectividad del fin perseguido.

En suma, si el único fin -y límite- de la pena es la intimidación no puede garantizarse que no vaya a aplicarse la pena a sujetos inimputables cuando ello sea necesario. Y, si lo que se pretende es garantizar la impunidad de estos sujetos en todos los casos, y no sólo generalmente, la afirmación de que tal necesidad se daría sólo en situaciones excepcionales no puede servir para justificar esta postura. Sin duda, contradice todas nuestras intuiciones de justicia el uso de la sanción penal sobre quien no ha podido tomar una decisión frente a la amenaza, pero se hace preciso un principio deontológico -es decir, inmune a las argumentaciones teleológico-preventivas- que pueda oponerse a la imposición de pena en estos casos.

Ello se evidencia, por ejemplo, en la postura de Mir, quien, después de plantearse la posibilidad de derivar la responsabilidad penal desde el criterio de la (ausencia de) necesidad de pena, termina por fundamentar su idea de la motivabilidad normal como fundamento de la culpabilidad con base en premisas deontológicas, afirmando que "es imprescindible introducir un momento normativo esencial: en un Estado social y democrático de Derecho no se considera justo llevar el deseo de prevención hasta castigar a quien actúa sin culpabilidad...el fundamento de dicha exclusión de la culpabilidad no puede verse en la imposibilidad total de prevenir los delitos, sino en un planteamiento valorativo que conduce a imponer un límite a la posibilidad de castigar a quien actúa sin culpabilidad....vulneraría el principio de igualdad real ante la ley el tratar a los inimputables desconociendo que carecen de dicha capacidad normal" ${ }^{\prime 34}$. Como puede apreciarse, en ambas líneas doctrinales se apela al presupuesto de la igualdad entre los sujetos, pero de forma muy distinta: mientras en las tesis consecuencialistas la desigualdad

\footnotetext{
${ }^{33}$ GIMBERNAT, ¿Tiene un futuro...? (nota 24), p. 157

${ }^{34}$ MIR PUIG, Función (nota 27), pp. 85-86 (Cursivas en el original).
} 
es entendida como un factum desde el que, supuestamente, puede derivarse empíricamente la ausencia de necesidad preventiva, en la afirmación de Mir la igualdad se asume como principio prescriptivo, el cual no puede vulnerarse aunque fuera necesario para la prevención.

Esta parecería ser, en cambio, la postura de la segunda de las soluciones de síntesis, si, como hemos dicho, la prevención general positiva incorpora el pensamiento retributivo -el principio de justicia que de él emana- sin abandonar las premisas de cariz teleológico, y sólo desde la pena ajustada a la culpabilidad han de plantearse efectos preventivos ${ }^{35}$. Se afirma, así, que la imposición de pena sólo sería necesaria cuando la impunidad del delincuente no pudiera asumirse por la población sin que se quebrantara su fidelidad al ordenamiento ${ }^{36}$. Pero, desde un planteamiento consecuente de la tesis según la cual la culpabilidad se fundamenta exclusivamente en la prevención, dicha proposición debe también invertirse: si el fin del Derecho penal es la estabilización de la conciencia jurídica y el reforzamiento de la fidelidad al ordenamiento de la colectividad, y ese fin preventivo se erige en exclusivo fundamento de la sanción, habrá de imponerse una pena, no sólo cuando no haya más remedio, sino siempre que sea necesario para ese fin de estabilización, y el hecho de que se haya cometido un delito implicará per se una presunción del debilitamiento de la norma; asimismo, la distribución de la pena -a quién y cómo- vendrá exclusivamente dada por dichas necesidades $^{37}$. Ello parece ser así en el primer Jakobs, para quien la "culpabilidad se fundamenta en la prevención general...y se mide conforme a dicha prevención" 38 . En otras palabras, el aspecto positivo -el "núcleo de verdad", en palabras de Jellinek- que yacía en la idea de retribución, consistente en la atención a la justicia de la medida del castigo, pudiendo así operar como límite a la tendencia expansiva de la lógica preventiva, es funcionalizado en

${ }^{35}$ De hecho, se ha afirmado que una de las razones del renacimiento de la prevención general positiva es su aspiración de erigirse en una solución al problema de las antinomias de la pena. Vid., así, CALLIES, Strafzwecke und Strafrecht, NJW 1989, p. 1339; PÉREZ MANZANO, Aportaciones de la prevención general positiva, en: Silva Sánchez (editor), Politica Criminal y nuevo Derecho penal, 1997, pp. 73 a 75; FEIJOO SÁNCHEZ, El injusto penal (nota 8), p. 38.

${ }^{36} \mathrm{Cfr}$. supra nota 28.

${ }^{37}$ En este sentido, FRISCH, Schwächen und berechtige Aspekte der positiven Generalprävention, en: Schünemann/von Hirsch/Jareborg (editores), Positive Generalprävention, 1998, p. 130, citando tanto a Roxin como a Jakobs, aunque matizando que hay diferencias importantes entre ambos.

${ }^{38}$ JAKOBS, Culpabilidad y prevención (nota 18), p. 78 . Vid. asimismo, JAKOBS, Strafrecht. Allgemeiner Teil. Die Grundlagen der Zurechnungslehre, 1991 (2a edición). 17/22, 17/31, aunque más matizadamente. Como luego veremos, la evolución de Jakobs en este aspecto puede llevar a interpretar sus actuales postulados de forma distinta, más cercanos a las soluciones de conflicto. 
aras de intereses preventivos, y lo que aparecían como premisas deontológicas pasan a convertirse en criterios de carácter exclusivamente funcional a dichos fines de estabilización, por lo que la potencialidad limitativa de las mismas se diluye: ¿cómo se resuelve el conflicto que surgiría si la aplicación de principios de justicia limitativos de la punición resultara disfuncional a dicha finalidad? ¿Habría de optarse por la punición de un inimputable si ello revirtiera efectos estabilizadores en el colectivo social? Desde la lógica exclusivamente consecuencialista que presenta este modelo la respuesta no puede ser sino afirmativa ${ }^{39}$.

Respecto de esos pretendidos efectos preventivos que conlleva la misma aplicación de criterios de justicia propugnados por esta postura doctrinal, la cuestión decisiva a plantear es qué contenido se atribuye a esos criterios y desde qué instancia argumentativa son inferidos. En este sentido, cabe distinguir, dentro de la prevención general positiva, dos formas diferentes de interrelación entre prevención y culpabilidad: fundamentación y compatibilidad. Así, no es lo mismo afirmar que la culpabilidad se fundamenta en criterios preventivos, que afirmar que el mantenimiento del principio de culpabilidad -derivado de argumentos deontológicos, externos por tanto a la racionalidad utilitarista- será compatible con los efectos preventivos de la pena ${ }^{40}$.

Dicha dualidad de criterios en la relación entre la culpabilidad y la prevención oscila y se mezcla en las diferentes concepciones mantenidas por la doctrina sobre la prevención general positiva, y viene a corresponderse con la distinción planteada por Mir Puig entre la función fundamentadora y la función limitadora de la prevención general positiva ${ }^{41}$. Desde la posición fundamentadora, que es la que ahora estamos sometiendo a consideración, los principios garantísticos de justicia son vaciados de contenido deontológico, y su comprensión se obtiene, como ya hemos visto, exclusivamente de la racionalidad final preventiva: "la pena adecuada a la culpabilidad es, por definición, la pena necesaria para la estabilización de la norma", manifiesta Jakobs $^{42}$. Así, en esta concepción, la idea de justicia se tergiversa y modifica en aras de su contingente virtualidad funcional, para convertirse en el sentimiento psico-social de lo justo en una situación concreta.

Dejando momentáneamente de lado la cuestión puntual acerca de si la concepción actual de Jakobs - sin duda el autor más controvertido en materia

${ }^{39}$ En igual sentido, WOLFF, Das neuere Verständnis von Generalprävention und seine Tauglichkeit für eine Antwort auf Kriminalität, ZStW 97 (1985), p. 803; FRISCH, Positiven Generalprävention (nota 37), p. 137.

${ }^{40}$ La distinción procede de BAURMANN, Folgenorientierung (nota 30), p. 26.

${ }^{41}$ Cfr. MIR PUIG, Función fundamentadora (nota 28), pp. 129 ss.

${ }^{42}$ JAKOBS, AT (nota 38) 17/31. 
de culpabilidad - puede inscribirse en este sector doctrinal, esa concepción de la culpabilidad fundamentada en la prevención es indudable en quienes, acogiendo los postulados funcionalistas de Durkheim, para quien la pena es una reacción pasional de venganza colectiva ${ }^{43}$, conciben la función de la pena como un instrumento para satisfacer los instintos de venganza de la colectividad generados tras una conducta delictiva ${ }^{44}$. Desde esta perspectiva, la idea de la retribución se transmuta en la "necesidad social de retribución" 45 , por lo que la intensidad y destinatarios de la pena se decidirá en función del grado de indignación o repulsa o temor que despierte la acción delictiva en la opinión pública ${ }^{46}$. Ya el mismo Durkheim expresó con claridad esta idea: "Cuando en los tiempos actuales se habla de un castigo justo, se está haciendo referencia en forma sublimada a ese sentimiento ancestral de ira colectiva, con la cual el grupo activa sus mecanismos de reacción y repulsa frente a actos desviados de sus representaciones comunes, reacción pasional que revierte en la cohesión afectiva de la comunidad" ${ }^{47}$.Tal como decíamos de la doctrina comunitarista - de la que Durkheim es evidente antecesor-, la libertad individual cede ante las necesidades de restablecer la cohesión social. En suma, si el componente deontológico de la culpabilidad se transforma en teleológico, nada queda, por tanto, de la referencia garantística que se predicaba de los principios inherentes a la retribución ${ }^{48}$.

${ }^{43}$ Vid. sobre ello, recientemente, ROBLES, Crimen y castigo (Ensayo sobre Durkheim), 2001, p. 89 ss.

${ }^{44}$ Sobre la concepción de la pena en Durkheim y su influencia en la discusión actual, remito a ALCÁCER GUIRAO, Los fines del Derecho penal (nota 9), pp.73 ss.

${ }^{45}$ Cfr., de nuevo, STRENG, ZStW 92 (1980), p. 649; ACHENBACH, Imputación individual (nota 26), p. 140.

${ }^{46}$ Claramente, GEPHART, Strafe und Verbrechen. Die Theorie Emile Durkheims, 1990, p. 127: En Durkheim "el principio de proporcionalidad es establecido a partir de la equivalencia entre la intensidad de la alteración del orden emocional y su reacción restitutiva". En el mismo sentido, FAUCONNET, Warum es die Institution "Verantwortlichkeit" gibt?, en: Lüderssen/ Sack (editores), Abweichendes Verhalten, II, 1, 1975, pp. 299. Sobre la relación entre el sentimiento de amenaza y las exigencias de seguridad ciudadana con la tendencia al aumento de rigor punitivo, cfr., por ejemplo, HASSEMER, El destino de los derechos del ciudadano en un Derecho penal "eficaz", Estudios penales y criminológicos, 1991, pp. 189 ss.

${ }^{47}$ Citado apud BULLASCH, Rechstsnorm und Rechtssystem in der Normentheorie Emile Durkheims, 1987, p. 72.

${ }^{48}$ Crítico con la sustitución de criterios garantísticos fundamentados en premisas axiológicas por la tergiversación de los mismos en función de exigencias irracionales de la colectividad, SILVA SÁNCHEZ, Aproximación, (nota 2), pp. 234 ss. También LUZÓN PEÑA, Prevención (nota 24), p. 154; PÉREZ MANZANO, Culpabilidad (nota 6), p. 182; BOCK, Ideen und Schimären im Strafrecht. Rechtssoziologische anmerkungen zur Dogmatik der positiven Generalprävention, ZStW 103 (1991), p. 647. 
Por otra parte, la pretensión de ofrecer una limitación frente a la tendencia al terror penal de la intimidación se muestra absolutamente ineficaz. Como acertadamente se ha objetado, dichas exigencias de venganza pueden implicar un mayor grado de punición que el necesario para la intimidación ${ }^{49} ; \mathrm{y}$ lo cierto es que el hecho de que la punición de inimputables o inocentes pueda ser funcional a los fines de estabilización y pacificación social apenas puede dudarse $^{50}$. Respecto a la punición de inimputables, la síntesis que pretende la prevención general positiva respecto a la culpabilidad implica aún menor potencialidad limitativa que la prevención de intimidación. Así, mientras que esta última teoría, al otorgar el mayor peso preventivo al momento de conminación penal abstracta, permite al menos la posibilidad de individualizar la relación subjetiva del autor con su acción en base a la motivabilidad de éste frente a la norma, ofreciendo tras la normativización del juicio de atribución de responsabilidad un substrato fáctico psicológico-individual empíricamente -al menos potencialmente- verificable ${ }^{51}$, la prevención general positiva, al centrarse en el momento impositivo de la pena, renuncia o relativiza esa individualización, relacionando al autor con su acción desde los efectos psico-sociales que se presume que ésta genera en la colectivi$\operatorname{dad}^{52}$. Ello se muestra con especial evidencia en las tesis de Jakobs ${ }^{53}$, para quien, asumiendo una total normativización funcional de la culpabilidad, los criterios individuales - estado psíquico, motivabilidad, conocimiento de la prohibición, etc.--, son, al menos nominalmente, sólo relevantes en tanto en

${ }^{49}$ Así LUZÓN PEÑA, Prevención (nota 24), p. 149; WOLFF, ZStW 97 (1985), p. 803. Otra opinión parece mantener HASSEMER, Variationen der positive Generalprävention, en: Schünemann/von Hirsch/Jareborg (editores), Positive Generalprävention, 1998, pp.36-37, reconociendo, no obstante, que tampoco la prevención general positiva está libre de la instrumentalización del individuo.

${ }^{50}$ Ello se manifiesta en el ejemplo hipotético de McCloskey, citado por NINO, Introducción (nota 13), p. 430, empleado para demostrar las consecuencias a que puede llevar el solo pensamiento preventivo: en un pueblo del sur de los Estados Unidos se produce una violación de una mujer blanca por un negro que es imposible hallar y, ante la amenaza de los blancos de linchar a un buen número de negros, el sheriff utilitarista inventa pruebas sobre un negro inocente para satisfacer las ansias de venganza de la colectividad.

${ }^{51}$ Sobre la relevancia de criterios empíricamente verificables para la racionalización y control de la arbitrariedad en el Derecho penal, cfr. BAURMANN, Schuldlose Dogmatik?, en Lüderssen/Sack (editores), Abweichendes Verhalten, IV, 1980, pp. 206 ss., 263; LÜDERSSEN, Das Strafrecht zwischen Funktionalismus und Alteuropäischen Prinzipiendenken, ZStW 107 (1995), pp. 893 ss.

${ }^{52}$ En similar sentido, aunque por distintas razones, HÖRNLE/von HIRSCH, GA 1995, p. 209.

${ }^{53}$ Sobre lo siguiente, cfr. JAKOBS, AT (nota 38) 17/18 ss. (concepto funcional de la culpabilidad y fines de la imputación subjetiva), 17/29 ss. (fundamento y (negación de función de límite) de la culpabilidad), 18/1 (imputabilidad). Cfr. también la exposición de PÉREZ MANZANO, Culpabilidad (nota 6), pp. 160 ss. 
cuanto es posible resolver el conflicto (quebrantamiento de la vigencia de la norma) de otra forma que no sea la imputación del autor como responsable del mismo y la consiguiente imposición de la pena. Así, el quebrantamiento de la expectativa producido por la acción delictiva de un inimputable puede procesarse como si de una expectativa cognitiva se tratara, asumiendo la sociedad tal frustración y no siendo, por ello, precisa la imposición de pena. Pero lo relevante no es, en sí, la condición de inimputabilidad del sujeto, ni, por tanto, su situación de desigualdad ante la capacidad para motivarse frente a la norma, sino la forma en que la colectividad asume el conflicto; en otras palabras, si la acción de un inimputable es idónea para desestabilizar la conciencia jurídica social, teóricamente el conflicto deberá solucionarse atribuyendo al autor inimputable la frustración de la expectativa: imponiéndose, por ello, la pena para estabilizar la vigencia de la norma ${ }^{54}$.

En suma, desde la versión de la prevención general positiva que pretende fundamentar sus propios límites toda garantía para el individuo desaparece en aras de la maximización funcional del fin de estabilización. como ha afirmado Stratenwerth, "si el principio de culpabilidad debe tener por lo menos la significación de un correctivo de las exigencias preventivas, no podrá fundamentarse en las exigencias de la prevención, sino que deberá basarse en otras consideraciones" ${ }^{\prime 5}$.

\section{Soluciones de conflicto}

\section{a) Una tesis de partida: la estabilidad depende de la legitimidad}

No obstante, es indudable que el sistema del Derecho penal, a la hora de tomar decisiones tanto legislativas como judiciales, no puede desvincularse de las representaciones de justicia asumidas por la sociedad, por lo que la idea de la aceptación de la imposición de la pena por parte de la sociedad debe ser un factor importante a la hora de ponderar su aplicación. Y ello atendiendo

\footnotetext{
${ }^{54}$ Como, en relación con la concepción "sistémica" de Jakobs, afirma KUNZ, ZStW 98 (1986), p. 825, la aplicación de la pena “queda sometida al cálculo preventivo". Ello es claro respecto de la tesis sostenida por el primer Jakobs acerca de los delincuentes impulsivos: cfr. JAKOBS, Culpabilidad y prevención (nota 18), p. 80, cuya exculpación sólo pudo ser admitida "una vez que la medicina hubo conseguido ofrecer remedios para su tratamiento"; esto es, una vez que pudo resolverse el conflicto de otra manera. Sobre el controvertido tratamiento de los delincuentes impulsivos en Jakobs, cfr. PEÑARANDA RAMOS/SUÁREZ GONZÁLEZ/ CANCIO MELIÁ, Consideraciones sobre la teoría de la imputación de Günther Jakobs, en: Jakobs, Estudios de Derecho penal, 1997, p. 54-55, destacando las modificaciones del mismo Jakobs al respecto. El mismo JAKOBS, Sociedad, norma y persona en una teoría de un Derecho penal funcional, 1996, p. 32, nota 19, reconoce ese carácter polémico.

${ }^{55}$ STRATENWERTH, El futuro del principio jurídico-penal de la culpabilidad, 1980, p. 112 .
} 
tanto a razones pragmáticas como de legitimación. Desde un punto de vista legitimatorio, porque en un Estado democrático ha de partirse de que el Derecho es un instrumento establecido por el autogobierno de los ciudadanos para la satisfacción y protección de sus intereses, por lo que, en la medida en que es creado por el consenso libremente expresado de los ciudadanos, sólo un orden jurídico cuya validez sea reconocida por los mismos será legitimo. Desde un punto de vista pragmático, porque todo sistema normativo democrático persigue el reconocimiento de sus normas y de sus consecuencias jurídicas como prescripciones y acciones racionales y razonables, y sólo cuando la actividad del Derecho penal armonice con las convicciones mantenidas sobre sus criterios rectores por la sociedad podrá consolidarse su aceptación y, por tanto, servir fructíferamente a los fines sociales a los que está llamado. En este sentido, podría afirmarse que la estabilidad del Derecho penal, es decir, el respeto a sus normas, dependerá en gran medida de su legitimidad, es decir, del libre reconocimiento de esa legitimidad por parte de sus destinatarios ${ }^{56}$.

\section{b) ¿Compatibilidad entre prevención y culpabilidad? producción} coyuntural de consenso vs. respeto al consenso

Tales son, en esencia, los fundamentos en los que se sostiene el criterio de la compatibilidad del principio de la culpabilidad con la finalidad preventiva, el cual parece corresponderse, como ya se mencionó, con la faceta limitadora de la prevención general positiva resaltada por algunos autores ${ }^{57}$. Desde esta posición se rechaza que la culpabilidad se fundamente únicamente en las necesidades de prevención, sino que se parte de que la culpabilidad, así como los criterios garantísticos implícitos o adyacentes a ésta, estando conformados desde presupuestos deontológicos, no son incompatibles con

\footnotetext{
${ }^{56} \mathrm{La}$ tesis citada, relativa a que en un derecho penal democrático la estabilidad depende la legitimidad recibe un mayor análisis en ALCÁCER GUIRAO, Los fines del Derecho penal (nota 9), pp. 216 ss. Posteriormente reiteraremos esa idea.

${ }^{57}$ Además de Mir Puig, pueden citarse - según el primero (las referencias bibliográficas son, en cambio, otras) - a ZIPF, Pallin-FS (nota 28), pp. 479 ss. ; HASSEMER, Einführung in die Grundlagen des Strafrechts, 1990, $2^{\mathrm{a}}$ edición, pp. 297 ss.; el mismo, Fines de la pena, pp. 117 ss. (p. 132 ss.); ROXIN, Die Wiedergutmachung im System der Strafzwecke, en: Schöch (editor), Wiedergutmachung und Strafrecht, 1987, p. 48; el mismo, Strafrecht. Allgemeiner Teil, 1997, $3^{\text {a }}$ edición, 2/27, 3/36 ss. No obstante, cabe dudarse de que estos autores asuman sólo una función limitadora de la prevención general positiva. Por un lado, prácticamente los tres admiten como fin legítimo la función ético-social, consistente en la internalización de los valores plasmados en las normas, fin que Mir Puig identifica con una concepción fundamentadora de la prevención general positiva (cfr. MIR PUIG, Función fundamentadora (nota 28), pp. 132 ss.). Por otro lado, en ocasiones oscilan entre el principio de culpabilidad como límite a la prevención y como correlato de la necesidad psico-social de estabilización.
} 
las necesidades de prevención, por el hecho de que dichos criterios limitativos - proporcionalidad, principio de responsabilidad subjetiva, principio de humanidad, etc.- se corresponden con las valoraciones de justicia mantenidas en la sociedad ${ }^{58}$.

En este sentido, no parece mantenerse, como la anterior versión de la prevención general positiva, que la pena haya de imponerse siempre que sea preciso y en el grado necesario para satisfacer los sentimientos de justicia (venganza), sino que se sostiene, por un lado, que las penas que sobrepasen las convicciones de justicia no podrán ser asumidas por la sociedad, fomentándose por tanto el no reconocimiento del Derecho - así Roxin ${ }^{59}$ o, por otro, que si el efecto preventivo no sólo ha de realizarse a través de la intimidación, sino también por medio de una "razonable afirmación del Derecho", la prevención habrá de limitarse por una serie de principios que deben restringir el Derecho penal en un Estado democrático de Derecho -así Mir Puig ${ }^{60}$.

Es debido a ese diferente punto de partida por lo que, a pesar de la semejanza terminológica con la versión fundamentadora de la prevención general positiva, esta comprensión parece acercarse más a las soluciones de conflicto que a las de síntesis. Aquí, en principio, ya no se sacrifican exigencias de justicia en aras de la satisfacción de los impulsos agresivos de la colectividad, sino que se parte de la tesis de que los principios garantísticos - no funcionalizados- obtenidos de la tradición filosófica liberal y explícita o implícitamente plasmados en los textos constitucionales, son los mantenidos por la sociedad en sus expectativas respecto a la actuación del poder punitivo estatal; y sólo a partir de esa tesis puede afirmarse el efecto preventivo de aceptación del ordenamiento. Lo acabado de afirmar se hace patente, por ejemplo, en la postura de Pérez Manzano, cercana a la de Mir en este punto, cuando pone de manifiesto que la puesta en práctica de criterios de prevención especial en la ejecución de la pena vendrá justificada en orden a la satisfacción de las exigencias sociales de justicia, ya que el hecho de que dicha función de la pena venga acogida por la Constitución española "puede ser interpretado como el resultado de un consenso sobre la necesidad de tener en cuenta la resocialización del delincuente" ${ }^{\text {61 }}$.

${ }^{58}$ ROXIN, AT (nota 57) , 3/47; MIR PUIG, Derecho penal. Parte General, 1996, $4^{\mathrm{a}}$ edición, 3/21; FRISTER, Die Struktur der voluntativen Schuldelement, 1993, p. 80 ss.; NEUMANN, Normative Kritik der Theorie der positiven Generalprävention, en: Schünemann/von Hirsch/Jareborg (editores), Positive Generalprävention, 1998, p. 148.

${ }^{59}$ Vid. ROXIN AT (nota 57) 3/47; el mismo, Wiedergutmachung (nota 57), p. 48. Similar, MÜLLER-DIETZ, Jescheck-FS (nota 8), p. 818.

${ }^{60}$ MIR PUIG PG (nota 58) 3/21. Similar, PÉREZ MANZANO, Culpabilidad (nota 6), pp. 288 ss.

${ }^{61}$ PÉREZ MANZANO, Culpabilidad (nota 6), p. 273-274. 
Como puede apreciarse, poco tiene que ver la noción de justicia mantenida por estos autores con el basado en la estabilización social a partir de la satisfacción de necesidades irracionales de venganza. La referencia a la idea del consenso puede permitirnos profundizar en esa diferencia. Así, mientras la funcionalización de las garantías individuales sirve a la producción coyuntural de consenso social, fomentando una aceptación emocional a corto plazo por la población, esta última posición, de talante liberal, parece asumir principios obtenidos en un consenso previo, consenso no puntual sino genérico y normativo, y es esta premisa la que permite afirmar a estos autores que la atención a dichos principios operará en consonancia con las valoraciones mantenidas por la sociedad, motivando, en consecuencia, a un reconocimiento a largo plazo del Derecho y sus instrumentos.

En resumen, la diferencia se cifra entre la que media en la producción de consenso coyuntural y el respeto a un consenso previo en torno a principios, lo que implica, a su vez, una diferente atención a la estabilidad y la legitimidad. Así, la noción de consenso de que parte la concepción de la compatibilidad remite al principio democrático de creación de las normas y principios por el autogobierno de los ciudadanos ${ }^{62}$, que se inserta, entonces, en el marco de la legitimidad, en cuanto es un criterio de legitimación del Derecho. Tal consenso previo es el que, respondiendo al modelo ideal del contrato social, aparece plasmado en la Constitución. En cuanto tal, la aplicación de la pena no puede pretender crear dicho consenso, sino que debe someterse el mismo. En cambio, la concepción de la fundamentación de la culpabilidad en la prevención acoge una noción plebiscitaria de consenso fáctico y coyuntural, que ha de generar la pena con su aplicación acomodada a esas necesidades de castigo, no estando basado, entonces, en presupuestos de aceptación racional sino de vinculación emotiva ${ }^{63}$.

${ }^{62}$ Dicho principio democrático es el que por ejemplo manifiesta HABERMAS, Facticidad $y$ validez (nota 10), p. 578: "Un contrato que cada individuo autónomo concluye con todos los demás individuos autónomos sólo puede tener por contenido algo que todos pueden racionalmente querer por ser interés de todos y cada uno. Por esta vía sólo resultan aceptables aquellas regulaciones que pueden contar con el asentimiento no forzado de todos".

${ }^{63}$ Como destaca KUNZ, ZStW 98 (1986), p. 825, esa estabilización a través de mecanismos irracionales en absoluto presupone la aceptación racional de los ciudadanos. En similar sentido, FRISCH, Positiven Generalprävention (nota 37), p. 136. En este sentido, se ha afirmado que estas concepciones de la prevención general positiva, las cuales responden a la asunción como deber ser, es decir, como fin legítimo de la pena, de procesos irracionales de socialización colectiva, deberían permanecer, para ser efectivas, como "teorías secretas", puesto que los procedimientos empleados por las mismas no serían aceptados racionalmente por los ciudadanos (BOCK, ZStW 103 (1991), p. 653; HÖRNLE/v. HIRSCH, GA 1995, p. 268). Desde un principio democrático, debe resaltarse que una "política criminal orientada a la legitimación debería ir tendencialmente dirigida a la aminoración de dicha irracionalidad, en vez de a reforzar aún más la neurosis colectiva" (BÖLLINGER, Generalprävention als sozialisationsfaktor? Zur Kritik der Dogmatisierung sozialwissentschaftliche Begriffe KrimJ 1, 1987, pp. 33 ss. ). 
Pues bien, sólo ese consenso previo y normativo -y no fáctico- es lo que otorgará el carácter deontológico de validez a los principios y normas acordados, no viendo su vigencia comprometida en función del 'estado cognitivo de justicia', por llamarlo de alguna forma, existente en la sociedad en un momento dado, perteneciente al ámbito fáctico. Siendo ello así, la idea mencionada de que la estabilidad depende de la legitimidad no se sostiene sobre datos empíricos, sino en la presunción normativa de que por lo general las acciones del poder punitivo que se acomoden a las pautas democráticamente acordadas serán reconocidas como legítimas por la sociedad ${ }^{64}$. Tal es la idea que plasma Rawls cuando postula que un orden justo tendería a la autorreproducción de su propia estabilidad ${ }^{65}$. Pero ello no implica que tal idea pueda ser tergiversada, buscando la estabilidad a corto plazo en aras de crear una producción maquiavélica de legitimidad, a través de las satisfacciones de las "necesidades irracionales de justicia" 66 .

En virtud de esa presunción, cabría mantenerse que, si bien la punición sometida a las exigencias irracionales de venganza fomentaría a corto plazo una estabilidad coyuntural, a largo plazo degeneraría en inestabilidad, puesto que la imagen que la colectividad se formaría del ius puniendi sería la de un instrumento opresor y coactivo ${ }^{67}$. Por el contrario, es sólo en el sentido de justicia como presunción de estabilidad a largo plazo, como sería aceptable la tesis de la prevención general positiva de que la justicia ejerce un efecto

${ }^{64}$ Como, por ejemplo, afirma GARCÍA AMADO, Del método jurídico a las teorías de la argumentación, AFD 1986, p. 174, "Si el fundamento del Derecho se sitúa en el reconocimiento y en el sometimiento libre al mismo por parte de hombres libres hay que concebir que toda norma general, del tipo que sea, ha de poder contar con el hipotético consenso de todos los sujetos". En sentido similar, KOLLER, Weinberger-FS (nota 17), p. 245.

${ }^{65}$ RAWLS, Teoria de la justicia (nota 10), pp. 548ss.; 306-307. Vid. también, WITTIG, Die Aufrechterhaltung gesellschaftlicher Stabilität bei John Rawls. Zwischen Gerechtigkeit Sinn und Strafe, ZStW 107 (1995), pp. 256-257.

${ }^{66}$ Ello es patente, por ejemplo, en representantes de esa prevención limitadora como PÉREZ MANZANO, Culpabilidad (nota 6), p. 213: "El argumento conforme al cual la culpabilidad debe ser mantenida porque tiene efectos general integradores, no puede ser esgrimido como fundamental, pues entonces la culpabilidad carece de valor en sí y el criterio determinante son las mudables exigencias sociales. La necesidad de mantener la culpabilidad es consecuencia de un argumento valorativo derivado de los principios del Estado de Derecho"; en igual sentido, la misma autora, en: Aportaciones de la prevención general positiva (nota 35), p. 86: "la razón principal del mantenimiento de la culpabilidad como límite de la pena no es de tipo empírico-social, su efecto preventivo-integrador, sino un argumento de tipo valorativo, deducido de los principios básicos del Estado social de Derecho". También en MIR PUIG, Función (nota 7), p. 85. Sin embargo, no puede decirse lo mismo, como ya fue resaltado, de otros autores supuestamente vinculados a esta versión limitadora de la prevención general positiva. Como ejemplo, baste confrontar la crítica de la primera autora citada a las tesis de Hassemer (PÉREZ MANZANO, Culpabilidad (nota 6), p. 207).

${ }^{67}$ Así, entre otros, VOSS, Symbolische Gesetzgebung (nota 4), p. 134. 
preventivo, tesis más plausible quizá en su vertiente negativa-que viene a ser la mantenida por la faceta limitadora de la prevención general positiva-, la cual afirma que una pena que resulte a todas luces injusta resultaría ser preventivamente contraproducente, puesto que minaría la confianza en el Derecho como un orden legítimo y sometido a principios de justicia ${ }^{68}$.

A sensu contrario, es también indudable que el respeto a esos principios de justicia conformados en el consenso normativo podrá generar inestabilidad a corto plazo, al poder no ser aceptada la impunidad de un quien no estaba en situación de culpabilidad. Aquí es donde las diferencias entre la tesis fundamentadora y la basada en la compatibilidad deben llegar a diferentes resultados. Desde ésta última, siguiendo el acervo del liberalismo político de la prioridad de la libertad individual frente al bien común, la estabilidad no puede obtenerse a cualquier precio, por lo que el respeto al principio de culpabilidad ha de mantenerse aun a costa de la inestabilidad a corto plazo. En cambio, con dicha funcionalización de criterios de justicia, propia de las soluciones de síntesis, nos aproximamos a la concepción que de las relaciones entre individuo y colectivo mantiene el comunitarismo, en cuanto que la esfera de libertades individuales no se conforman frente al poder estatal o las necesidades de bien común del colectivo, sino desde esas necesidades. Además, la tergiversación de esos criterios de justicia en satisfacción de necesidades de castigo en aras del fomento de estabilidad coyuntural pervierte también el principio de autonomía política propio del liberalismo, del que parte el presupuesto democrático citado del autogobierno, en cuanto apela a procesos irracionales de adhesión. Una diferencia esencial entre el liberalismo y el comunitarismo es que en el primero, el mandato de la autonomía política exige que el ordenamiento jurídico, tanto sus normas como sus medios, sea susceptible de reconocimiento por el acuerdo de todos los intervinientes en el tráfico jurídico-social, para lo que es preciso que el Derecho esté asentado en presupuestos susceptibles de una aceptación racional y que responda a los intereses de los ciudadanos ${ }^{69}$. Frente a esta exigencia democrática, aquellas concepciones que aspiran, a través del castigo, al fomento de un clima emocional de consenso frente al chivo expiatorio en que se convierte el delincuente, no son sino una "racionalización encubridora del funcionamiento de dichos mecanismos irracionales"70, lo que vulnera el principio de autonomía política, y pervierte la idea de un Derecho penal

\footnotetext{
${ }^{68}$ Así, por ejemplo, KUNZ, ZStW 98 (1986), p. 832.

${ }^{69}$ Más ampliamente sobre ello, ALCÁCER GUIRAO, Los fines del Derecho penal (nota 9), pp. 160 ss.

${ }^{70}$ LUZÓN PEÑA, Prevención general y psicoanálisis (nota 24), p. 153. Critico también con el fin de integración, SILVA SÁNCHEZ, Aproximación (nota 2), p. 235
} 
democrático, degenerando en un Derecho autoritario y tecnocrático. Con la exclusiva fundamentación preventiva del principio de culpabilidad, el ciudadano, sometido a las necesidades estratégicas de cohesión social, es privado de su autonomía, de su carácter de sujeto copartícipe en las relaciones jurídicas, y pasa a convertirse en objeto, en mero factor funcional de la prevención $^{71}$.

Debe quedar claro, en conclusión, que si se pretende una fundamentación sólida y vinculante del respeto a las garantías del individuo y no sólo a los intereses de la colectividad, las soluciones de síntesis no son viables. Respecto de si esas garantías de naturaleza deontológica son compatibles con los fines preventivos, a mi juicio es obligado reconocer que en muchos casos ello no será así, que la pena justa no ejercerá efectos preventivos, al menos en relación a la estabilidad a corto plazo $^{72}$. Es decir, que debe asumirse el conflicto entre prevención y garantías ${ }^{73}$ : ninguna teoría de la prevención general está capacitada para limitarse a sí misma, por lo que todas precisan de límites externos a las mismas, si no se quiere renunciar a la protección del individuo frente a la colectividad y al poder estatal ${ }^{74}$. En cualquier caso, lo que también han mostrado las anteriores consideraciones es que la única forma de armonizar prevención y culpabilidad pasa por el presupuesto de la autonomía política, basada en el mutuo reconocimiento como agentes socialmente competentes. Antes de intentar abordar esa propuesta, conviene que nos detengamos en la

${ }^{71}$ Así, especialmente, BURKHARDT, Charaktermangel und Charakterschuld, en: Lüderssen/Sack, Von Nutzen und Nachteil der Sozialwissenschaften für das Strafrecht, 1980, p. 121.

${ }^{72}$ En igual sentido, FRISCH, Positiven Generalprävention (nota 37), p. 137, poniendo el discutido ejemplo de los delincuentes impulsivos, y destacando que una teoría de la prevención general positiva que parta de las representaciones sociales de justicia de cara a la estabilidad a corto plazo tendrá que asumir que a veces habrá de castigar a pesar de la injusticia del castigo, por cuanto lo relevante es la prevención.

${ }^{73}$ así, entre otros, BAURMANN, Strafe im Rechtstaat (nota 20), p. 112; SILVA SÁNCHEZ, Aproximación (nota 2), p. 250: "Su relación es, por el contrario...dinámica, de confrontación permanente".

${ }^{74}$ Así, entre otros, ROXIN, Sinn und Grenzen (nota 10), p. 21: un "derecho de protección frente al Estado"; el mismo, AT (nota 57) 3/31; BURKHARDT, GA 1976, p. 322; STRATENWERTH, El futuro (nota 55), p. 112; BAURMANN, Folgenorientierung (nota 30), p. 50; el mismo, Schuldlose dogmatik? (nota 51), p. 211; HOERSTER, Zur Begründung staatlichen Strafens, Weinberger-FS, p. 231; KUNZ, ZStW 98 (1986), pp. 827-8, quien, después de destacar que "la prevención no puede inferir límites de sí misma", afirma que ese es el tema central de la actual discusión sobre las teorías de la pena: "la búsqueda de reglas normativas que puedan domesticar un Derecho penal preventivo desde un Estado de Derecho" ; KIM, Zur Fragwürdigkeit (nota 31), p. 122; PÉREZ MANZANO, Culpabilidad (nota 6), p. 159; BOCK, ZStW 103 (1991), p. 656; SILVA SÁNCHEZ, Aproximación (nota 2), pp. 210 y 240: "La prevención...sea positiva o negativa 'no se limita a sí misma' ”; PAPAGEORGIOU, Schaden und Strafe (nota 26), p. 15. 
concepción de Jakobs, cuya evolución en materia de culpabilidad presenta una interesante aproximación a estos presupuestos mencionados.

\section{d) Del sistema social a la persona. Consideraciones sobre la concepción de Jakobs}

De sobra conocidas son las provocadoras tesis de Jakobs en esta materia, algunas de las cuales han sido ya mencionadas, situándolo dentro de las soluciones de síntesis. La tesis central de Jakobs es la de un concepto completamente funcional de culpabilidad: el fundamento y límites de la responsabilidad individual depende de la autoconfiguración de la sociedad; es decir, del consenso social acerca del derecho y la justicia; por tanto, se determina en función de la necesidad de estabilización del orden social ${ }^{75}$. Esa acentuación en la funcionalización de principios limitadores de la pena en virtud del sistema social ha generado toda una estela de valoraciones críticas sobre su postura que, en la línea de las objeciones realizadas habitualmente sobre la teoría de sistemas, han destacado la instrumentalización del individuo en aras del colectivo social, considerando a aquél, entonces, no en su subjetividad, sino como un mero "objeto", cuyos derechos y libertades se definirían en virtud de esas necesidades de estabilización del sistema ${ }^{76 / 77}$.

En la medida en que Jakobs ha venido asumiendo los presupuestos funcionalistas de la teoría de sistemas $^{78}$, considero que se ha hecho merecidamente acreedor de esas críticas. Lo característico del funcionalismo sociológico - del de Durkheim o T. Parsons, pero también del Luhmann- es situar como referente central de decisión a la sociedad en detrimento del individuo ${ }^{79}$, por

${ }^{75}$ Cfr. JAKOBS, El principio de culpabilidad (nota 18), pp. 384 s. Sobre esa caracterización, vid. GÜNTHER, Freiheit und Schuld in der Theorie der Positive Generalprävention Schünemann/von Hirsch/Jareborg (editores), Positive Generalprävention, 1998, pp. 156 ss.

${ }^{76}$ Críticas respecto a la postura de Jakobs en materia de culpabilidad se encuentran, entre otros lugares, en STRATENWERTH, El futuro (nota 55), pp. 112 ss.; KIM, Fragwürdigkeit (nota 31), pp. 96 ss ; PÉREZ MANZANO, Culpabilidad (nota 6), pp. 168 ss., pp. 174 ss. ; SCHÜNEMANN, La función del principio de culpabilidad en el Derecho penal preventivo, en: Schünemann (compilador), El Sistema moderno de Derecho penal: cuestiones fundamentales, 1991, p. 160 ; STÜBINGER, Nicht ohne meine Schuld!, KJ 1993, pp. 33 ss.; ROXIN, AT (nota 57) 19/31 ss.; HIRSCH, El principio de culpabilidad y su función en Derecho penal, NDP 1996, pp. 31 ss.

${ }^{77}$ Acerca de las críticas a la teoría de sistemas en ese aspecto, vid. ALCÁCER GUIRAO, Facticidad y normatividad, NDP 1998, pp. 402 ss., y la bibliografía allí citada.

${ }^{78}$ Ello de forma muy intensa en sus primeros escritos sobre culpabilidad: cfr. Culpabilidad y prevención (nota 18), p. 78 ss.

${ }^{79}$ En este sentido, por ejemplo, SCHELSKY, Systemfunktionaler, antrhopologischer und personfunktionaler Ansatz der Rechtssoziologie, en: Maihofer (editor), Die Funktion des Rechts in der modernen Gesellschaft, Jahrbuch für Rechstsoziologie und Rechtstheorie, 1, 1970, pp. 54-56; KIM, Zur Fragwürdigkeit (nota 31), p. 24. 
lo que la derivación de principios garantísticos - que operan, como ya se mencionó, como esferas de protección del individuo frente a necesidades colectivas - de ese referente llevará necesariamente a establecerlos en función de las necesidades de estabilización y, por ello, a que pierdan ese carácter de límites externos a la lógica preventiva. Como he puesto de manifiesto en otro lugar $^{80}$, característico de la racionalidad sistémica es que aporta un método de análisis basado exclusivamente en el criterio de la funcionalidad, por lo que la referencia a criterios deontológicos aparece como un elemento extraño a la lógica sistémica ${ }^{81}$. En efecto, si todo elemento del sistema es valorado en base a su funcionalidad para la estabilización del mismo, la racionalidad valorativa, caracterizada por ser un criterio de legitimación basado, como dijimos, en principios independientes de la satisfacción de resultados, no tiene cabida en la argumentación sistémica, sino que los principios éticos y las garantías limitativas obtendrán su vigencia -y su contenido- en tanto en cuanto sean funcionales al fin de la conservación del sistema. Como, en este sentido, se ha podido afirmar: "la Wertrationalität aparece como función de la Zweckrationalität"s2.

La influencia de Luhmann, muy presente en la primera aproximación de Jakobs a la controversia entre Culpabilidad y prevención (1976), ha venido, en cualquier caso, cediendo con la evolución de su pensamiento ${ }^{83}$, dotando, en los últimos años, de mayor relevancia a una configuración interpersonal de la sociedad que a una sistémica. A mi entender, esa evolución vendrá modificar también el discurso acerca de la relación entre ambos polos del conflicto.

Jakobs parte del presupuesto de que en un sociedad democrática y pluralista - es decir, en una sociedad con un considerable grado de estabilidad-, la imagen del ciudadano como destinatario de las normas es la de una persona respetuosa del Derecho, por lo que de todos, prima facie, puede presuponerse una motivación fiel a las normas que regulan la convivencia, así como la

\footnotetext{
${ }^{80}$ Para un mayor desarrollo de lo afirmado en el texto, cfr. ALCÁCER GUIRAO, NDP 1998, pp. 402 ss.

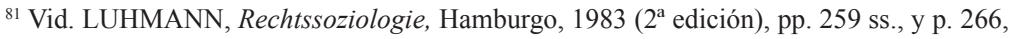
donde afirma que la idea de la legitimidad ha de entenderse funcionalmente, de forma que ya no puede concebirse como un criterio de justificación externo al sistema político, sino como una prestación del mismo. Cfr., además, NAVAS, Der Begriff der Moral bei Niklas Luhmann, Jahrbuch für Recht und Ethik, I, 1993, pp. 303-304; LÓPEZ CALERA, Funciones del Derecho, en Derecho y justicia, Garzón Valdés/Laporta (edit.), Madrid, 1996, p. 462.

${ }^{82}$ Así, SILVA SÁNCHEZ, Política criminal en la dogmática (nota 3), p. 21. Similar, KIM, Zur Fragwürdigkeit (nota 31), p. 25 y crítico en p. 29. Cfr. también NAVAS (nota , p. 304, resaltando el Kontingentismus de toda referencia a principios propio de la teoría de Luhmann.; GARCÍA-PABLOS, Derecho penal. Introducción, Madrid, 1995, p. 383 .

${ }^{83}$ Cfr., por ejemplo, JAKOBS, Sociedad, norma y persona (nota 54), 1996, p. 16.
} 
competencia para mantener esa motivación. Desde esta premisa, la culpabilidad se define como la responsabilidad por un déficit de motivación jurídica dominante por quien es competente para ello ${ }^{84}$.

Dicha competencia se define como la capacidad de cumplir con lo prescrito $^{85}$, e inversamente, como la capacidad para poner en cuestión la validez de la norma, siendo entonces sinónimo de la imputabilidad ${ }^{86}$. Lo determinante, entonces, para establecer las relaciones entre prevención y culpabilidad, es cómo se rellena de contenido ese concepto de competencia. Aquí es donde, a mi juicio, radican las diferencias en la evolución de sus planteamientos.

En un primer momento, en la obra citada, para Jakobs la noción de autonomía personal, presupuesto de la competencia, aparecía como un concepto sólo conformado en torno a las necesidades de estabilización del sistema: la autonomía, afirmaba entonces, "sólo es atribuida como capacidad si ello es adecuado a los fines, y sólo puede faltar cuando exista la posibilidad de un procesamiento diferente del conflicto" ${ }^{\$ 7}$. En otras palabras, el ámbito de la competencia, esto es, de la imputabilidad, venía exclusivamente dado por la funcionalidad para el sistema. Con ello, al igual que otras soluciones de síntesis, los principios de justicia que conforman la culpabilidad, perdían su carácter de "barrera de protección" frente al poder estatal, al determinarse la capacidad de motivación en virtud de los fines preventivos de éste.

Un primer tránsito a esa comprensión interpersonal, y no sistémica, de la sociedad, se da cuando Jakobs introduce de forma clara el factor de la igualdad como requisito de la competencia ${ }^{88}$ : "ser imputable quiere decir ser definido como un igual" $"$. En cualquier caso, ya hemos tenido ocasión de ver que la utilización de la igualdad como presupuesto de la aplicación de la pena no implica necesariamente un potencial limitador, por cuanto esa igualdad puede argumentarse, no sólo como un principio garantístico -al considerar ilegítimo castigar a quien no está en condiciones de igualdad motivatoria-, sino también desde un parámetro preventivo -el mencionado "proceso de identificación" de Gimbernat-.

En Jakobs, por su parte, podrán encontrarse ambas aproximaciones. Así, en un primer momento la igualdad será entendida por Jakobs como factor

${ }^{84}$ JAKOBS, AT (nota 38) 17/1 ss.; el mismo, El principio de culpabilidad (nota 18), p. 367, 383; el mismo, Sociedad, norma y persona (nota 54), pp. 63-64.

${ }^{85}$ En este sentido, Jakobs asume la competencia como el equivalente del libre albedrío: cfr. JAKOBS, El principio de culpabilidad (nota 18), p. 382.

${ }^{86}$ JAKOBS, AT (nota 38) 17/48.

${ }^{87}$ Culpabilidad y prevención (nota 18), p. 85.

${ }^{88}$ Ese aspecto es acentuado también por PEÑARANDA RAMOS/ SUÁREZ GONZÁLEZ/ CANCIO MELIÁ, Consideraciones sobre la teoría de la imputación de Günther Jakobs (nota 54), pp. 49 ss..

${ }^{89}$ JAKOBS, AT (nota 38), 17/48. 
funcional a la prevención: "Dada una situación motivatoria igual en cuanto a su género en sus rasgos esenciales, la infracción de la norma por un sujeto ejemplifica la infracción de la norma de cualquier autor equiparable, y por ello constituye un ataque a la validez de la norma en relación con cualquiera"90. Así, los inimputables no quebrantarán la norma porque no serán considerados como iguales por el resto de los actores, pero, en dicha argumentación, la idea de la igualdad carece de un anclaje deontológico que proscriba el castigo de inimputables en caso de que fuera necesario. De igual modo, la calificación de inimputable dependerá de instancias de decisión preventivas.

Es en su contribución posterior sobre El principio de culpabilidad (1993) cuando Jakobs parece dar un paso más en relación con la igualdad como principio. Sólo quienes pueden considerarse como iguales de cara a la motivación por normas pueden ser sujetos competentes de comunicación de cara a la vigencia de la norma: la competencia es una mutua imputación como personas responsables. Por esa razón, sólo la pena que trate al autor como persona $-\mathrm{y}$ no como naturaleza- se situará también en el mundo de lo comunicativamente relevante, como réplica con sentido al delito. "En el hecho de que es tratado como una persona, esto es, de que se le reconoce como un igual, "se honra al delincuente como ser racional", afirma Jakobs acogiendo el clásico aforismo de Hegel ${ }^{91} / 92$.

${ }^{90}$ JAKOBS, AT (nota 38), 17/48.

${ }^{91}$ JAKOBS, El principio de culpabilidad (nota 18), p. 388.

${ }^{92} \mathrm{Creo}$ indudable concluir que ya con esa afirmación pueden hallarse referentes de valor. No obstante, Jakobs introduce esas consideraciones dentro de un marco metodológico descriptivo, entendiendo que sólo se limita a describir "las condiciones de funcionamiento de toda sociedad", independientemente de la legitimidad del orden jurídico (vid. JAKOBS, El principio de culpabilidad (nota 18), p. 387). Por ello, afirma, su formulación de la culpabilidad es "formal", y "no tiene más peso que el valor del orden que se pretende estabilizar" (JAKOBS, El principio de culpabilidad (nota 18), p. 384 Frente a esa culpabilidad formal, habría que distinguir, entonces, una "culpabilidad material", la cual "presupone normas legítimas" (JAKOBS, El principio de culpabilidad (nota 18), p. 386). Siendo así, la noción de persona, en cuanto que esa una concepción abstracta y normativa, podría rellenarse de diferente contenido, es decir, de un mayor o menor ámbito de derechos frente a la colectividad. Lo determinante será, entonces, concretar cuáles han de ser los criterios de legitimidad del orden jurídico, cuestión que Jakobs no entra a responder. Ello abre, ciertamente, todo un campo de análisis que excede de lo que estas páginas pueden abarcar. Por lo demás, esa opción metodológica "descriptivo-analítica" (propia de la teoría de sistemas) es resaltada también por MÜSSIG, Schutz abstrakter Rechtsgüter und abstrakter Rechtsgüterschutz, 1994, p. 238 ("la teoría de la prevención general positiva ... es un modelo formal y positivista en la medida en que da por supuesta, es decir, no convierte en el tema a tratar, la configuración concreta de la sociedad"), p. 142 (: "La teoría de la prevención general positiva es un concepto positivista: presupone el Derecho y la forma de la sociedad, en el sentido de que son éstos los que determinan el contenido y el ámbito del Derecho penal"). Sobre si una metodología descriptiva es adecuada para el objeto al que pretende aplicarse: el Derecho penal, cfr. ALCÁCER GUIRAO, NDP 1998, pp. 420 ss., respondiendo negativamente. 
Además, con relación a la utilización de mecanismos irracionales de adhesión, y la consiguiente vulneración de la autonomía política, Jakobs se manifiesta abiertamente en contra, y no por razones preventivas: "la dignidad humana, si tiene un contenido mínimo, es desde luego incompatible con la prohibición de aclarar la lógica de la comunicación"93.

Pero ha sido en los últimos años cuando Jakobs ha enfatizado la imagen de la sociedad desde una perspectiva interpersonal, antes que sistémica. "La interpretación del delincuente como una persona que, como igual, expresa un sentido que tiene validez general y se ve contradicho con la pena, está vinculada a una concepción (...) en que la sociedad no aparece, o no sólo, como comunicación instrumental, sino también como comunicación que reconoce": como comunicación personal ${ }^{94}$. ¿En qué consisten las diferencias entre ambas formas de comunicación? La comunicación instrumental es la orientada a perseguir fines, en la cual el otro es mero "objeto de cálculo estratégico"; en cambio, en la comunicación personal se trata al otro como igual, en virtud de un mutuo reconocimiento como personas autónomas, dotadas de competencia de discurso. Y es sólo esta comunicación personal la que permite crear un orden normativo externo a las preferencias individuales, que establecerá las reglas de la convivencia a las que todos tienen que someterse ${ }^{95}$.

Con dicha comprensión de lo social, el principio de igualdad como presupuesto de la culpabilidad parece venir a adquirir un perfil deontológico, independiente de la satisfacción de fines preventivos, por cuanto ya no está generado desde las necesidades del colectivo, no siendo entonces susceptible de ser sometido a ese cálculo estratégico, sino que está anclado en un proceso de decisión intersubjetivo sometido a condiciones de imparcialidad, del que emanará una regla que vinculará a todos por igual. El principio de igualdad forma parte, entonces, de ese consenso normativo previo acerca de los principios esenciales de la convivencia: normas y principios de aplicación de las mismas. Desde esta perspectiva, la idea de base de que la culpabilidad debe conformarse en función del fin de reafirmación de la identidad normativa de la sociedad, no tendría por qué limitar la construcción de la culpabilidad desde los fines preventivos, sino que, desde un plano más genérico, en esa identidad normativa estarían ya incluidos esos principios

\footnotetext{
${ }^{93}$ JAKOBS, El principio de culpabilidad (nota 18), p. 388. Ello ya figuraba, aunque con menor énfasis, en AT (nota 38) 17/48.

${ }^{94}$ JAKOBS, Sociedad, norma y persona (nota 54), p. 69.

${ }^{95}$ JAKOBS, Sociedad, norma y persona (nota 54), p. 70 y ss. Sobre las diferencias entre ambas formas de relación social, cfr. HABERMAS, Teoría de la acción comunicativa, I, 2001, $2^{\mathrm{a}}$ edición, pp. $136 \mathrm{ss}$.
} 
de justicia. Expresado de otra forma, en esa identidad normativa estaría ya plasmado el conflicto entre prevención y garantías, por lo que la aplicación de la pena, si quiere venir a reafirmar esa identidad, debería llegar a un equilibrio entre prevención y garantías ${ }^{96}$.

\section{La culpabilidad en un Derecho penal democrático}

\section{Culpabilidad y prevención: el doble fin del Derecho penal}

Con esa última concepción manifestada por Jakobs, su sistema adopta los perfiles propios de un Estado liberal y democrático ${ }^{97}$. Característico de la legitimación de instituciones públicas de una concepción liberal y democrática es, como ya hemos visto, que esas instituciones respondan a los intereses de los ciudadanos, en virtud de un acuerdo realizado en condiciones de igualdad e imparcialidad que represente las aspiraciones de todos los ciudadanos, tal como plasma la imagen del contrato social ${ }^{98}$. Bajo ese criterio de legitimación late una exigencia previa, que es la que Jakobs plasma con la noción de la comunicación personal: el mutuo reconocimiento de todos los coasociados como sujetos libres y dotados de una capacidad reflexiva, así como de una situación de igualdad de cara a ver representados sus intereses en los acuerdos ${ }^{99}$.

En un Derecho penal basado en la comunicación interpersonal, entonces, la legitimación de la pena - de sus fines y de sus criterios de aplicación- no se establece "desde arriba", es decir, desde la prioridad de intereses del colectivo frente a la libertad individual (propio de esa comunicación estratégica, desde la que el individuo es introducido como objeto de un cálculo de necesidades sociales), sino "desde abajo": del acuerdo interpersonal de todos los ciudadanos bajo condiciones de equidad ${ }^{100}$. Ese cambio de pers-

${ }^{96}$ Ello parece entenderse así por JAKOBS, Sociedad, norma y persona (nota 54), p. 66, nota 52.

${ }^{97}$ Así, GÜNTHER, Freiheit und Schuld (nota 75), p. 169.

${ }^{98}$ Cfr. por todos RAWLS, Teoría de la justicia (nota 10), pp. 28, 75, y passim.

${ }^{99}$ Vid., en este sentido, KUNZ, ZStW 98 (1986), pp. 833-834; HÖRNLE/von HIRSCH, GA 1995, p. 267; KINDHÄUSER, La culpa penal en un Estado democrático de Derecho, en: Kindhäuser, Derecho penal de la culpabilidad y conducta peligrosa, 1996, pp. 36-38, 43.

${ }^{100}$ Una idea similar expresa Maihofer. Ya fue mencionado que el utilitarismo está basado en una racionalidad teleológica, caracterizada por derivar el juicio sobre la corrección de una acción en función de la satisfacción del mayor bien para el mayor número; frente a ello, en el liberalismo la fundamentación de principios y normas responde a un carácter deontológico, a partir de ese acuerdo intersubjetivo basado en la razón práctica de los individuos y de carácter vinculante (independiente de la búsqueda de resultados preventivos). Ello guarda relación con los dos criterios de legitimación que vimos en la introducción, la legitimidad instrumental y la legitimación valorativa, en el sentido de que, como afirma Maihofer, mientras la racionalidad instrumental responde a una perspectiva decisoria subjetiva - ya de carácter individual, 
pectiva conlleva, de una parte, que la pena y su imposición debe poder ser legitimada no sólo frente a la sociedad en su conjunto -como víctima potencial del delito-, sino también frente a los sujetos a quienes se le impone, en el sentido de que también frente a ellos aparezca como una medida necesaria, razonable y legítima ${ }^{101}$, lo cual sólo podrá darse cuando todos los implicados en el proceso de comunicación -potenciales víctimas y potenciales delincuentes- asuman la pena y su aplicación como emanada de un acuerdo realizado en condiciones de imparcialidad, porque sólo entonces responderá a los intereses de todos los implicados ${ }^{102}$. Sólo de esa forma, en suma, se reconoce a la persona inmersa en el castigo como ciudadano, es decir, como sujeto de comunicación interpersonal, y no como mero objeto de comunicación estratégica.

Desde estos presupuestos ideológicos, la prevención no puede ser el único criterio legitimador del ius puniendi, porque entonces sólo se atenderían a los intereses de las potenciales víctimas, sino que junto a la misma debe concurrir un fundamento de legitimidad independiente- ajeno a esa lógica preventiva ${ }^{103}$-basado en la protección de la libertad del delincuente frente al poder estatal ${ }^{104}$. Dicha fundamentación, que consagrará la validez

ya colectiva, como es el caso de la sanción penal -, la racionalidad valorativa viene dada por una perspectiva decisoria intersubjetiva. Cfr. MAIHOFER, Die gesellschaftliche Funktion des Rechts (nota 3), p. 27. En sentido similar, SILVA SÁNCHEZ, Politica criminal (nota 3), pp. 21-22. Vid. asimismo, en general, sobre la fundamentación intersubjetiva de valores, por oposición a una concepción ontológica de los mismos, HOERSTER, Rechtsethik ohne Metaphysik ,JZ 1982, pp. 265 ss.

${ }^{101}$ Así, SCHÜNEMANN, La función del principio de culpabilidad (nota 76), pp. 160-161: "La pena criminal debe legitimarse de modo que su imposición a un concreto ciudadano (...) aparezca como una medida justa y defendible también frente a él"; NEUMANN, Normative Kritik der Theorie der positiven Generalprävention (nota 58), p. 150.

${ }^{102}$ NEUMANN, Normative Kritik der Theorie der positiven Generalprävention (nota 58), p. 152.

${ }^{103}$ Así, BURKHARDT, GA 1976, p. 335; SCHÜNEMANN, La función del principio de culpabilidad (nota 76), p. 162; KUHLEN, Anmerkungen zur positiven Generalprävention, en: Schünemann /von Hirsch/Jareborg (editores), Positive Generalprävention, 1998, p. 59.

${ }^{104}$ En este sentido, también BAURMANN, Schuldlose Dogmatik? (nota 51), p. 210: "La única y exclusiva persecución de fines preventivos a través de las instituciones jurídicas llevaría inevitablemente a la intolerable vulneración de otros fines sociales: el daño que causaría el criterio de instrumentalización de los medios dirigidos a la efectividad político-criminal, sería mucho más gravoso que su beneficio. El bien jurídico precisa, desde esta perspectiva, de una doble protección: 'a través del Derecho penal y frente al Derecho penal, cuya aplicación excesiva llevaría a la situación que pretende evitar", citando a Roxin. En sentido similar, KUNZ, ZStW 98 (1986), p. 829, quien resalta que el único criterio para encontrar límites firmes a la prevención es partir del hecho de que la prevención no puede ser el único fundamento normativo de la pena. Críticos también con un Derecho penal orientado únicamente a la efectividad preventiva, dada la supeditación a la misma de garantías individuales, CALLIES, NWJ 1989, p. 1339; PAPAGEORGIOU, Schaden und Strafe (nota 26), p. 15; HASSEMER/MUÑOZ CON- 
de las garantías y en particular del principio de culpabilidad, operará como límite en el ámbito de la teoría del fin de la pena y, por tanto, en relación de conflicto con los fines de prevención, pero, adelanto ya, habrá de considerarse además como un fin propio del Derecho penal, junto a la protección de bienes jurídicos. Como se ha afirmado: "si el Derecho penal sirve a la protección del individuo frente al poder estatal y de la sociedad frente a los ataques individuales, es necesario intentar un equilibrio entre lo favorable al reo y lo favorable a la sociedad" ${ }^{105}$.

La posible coexistencia de dos fines contrapuestos del Derecho penal parece responder, en realidad, a una plausible reconstrucción de lo que se acordaría por la sociedad, como grupo de individuos racionales que se reconocen mutuamente capacidad de comunicación social ${ }^{106}$; es decir, lo que habría de considerarse legítimo desde presupuestos liberales y democráticos. Indudablemente, la tensión entre prevención y garantías viene debida a que cada opción representa los intereses contrapuestos que diferentes grupos sociales tendrían respecto de la labor del Derecho penal. Por un lado, para el interés de las víctimas potenciales, generalmente respetuosos del Derecho, lo racional sería un Derecho penal orientado hacia una prevención lo más eficaz posible, que protegiera, al precio que fuera, sus intereses de los ataques de terceras personas. Por el contrario, para el grupo representado por

DE, Introducción a la criminología y al Derecho penal, 1989, p. 137; BAURMANN, Strafe im Rechtstaat (nota 20), p. 135; SILVA SÁNCHEZ, Aproximación (nota 2), pp. 241 HASSEMER, El destino de los derechos del ciudadano (nota 46), pp. 183 ss., passim.

${ }^{105}$ PÉREZ MANZANO Aportaciones de la prevención general positiva (nota 35), p. 88; la misma, Culpabilidad (nota 6), p. 292. dicha idea dista mucho de ser novedosa: cfr. SILVA SÁNCHEZ, Aproximación (nota 2), pp. 241 ss., quien atribuye al Derecho penal el "fin de reducción de la propia violencia estatal"; BAURMANN, Schuldlose Dogmatik? (nota 51), p. 255; CALLIES, NJW 1989, pp. 1338 ss.; HASSEMER, Einführung (nota 57), p. 326; HASSEMER/ MUÑOZ CONDE, Introducción (nota 104), p. 137; FROMMEL, Schüler-Springorum-FS (nota 26), p. 274, siguiendo a Hassemer. Cfr. asimismo ROXIN, AT (nota 57), 7/69, quien afirma que "la limitación jurídica de la violencia estatal es, por sí mismo, un fin de una política criminal propia de un Estado de Derecho"; o MIR PUIG, Sobre el principio de intervención mínima, en: Mir Puig, El Derecho penal en el Estado Social y Democrático de Derecho, 1994, p. 151: "Ello enlazaría con la tradición liberal que arranca de Beccaria y que postula la humanización del Derecho penal: se parte de la idea de que la intervención penal supone una intromisión del Estado en la esfera del ciudadano, que sólo resulta tolerable cuando es estrictamente necesaria - inevitable - para la protección del mismo ciudadano. (Tras ello se halla la convicción de que es preciso defender al ciudadano del poder coactivo del Estado)."

${ }^{106}$ Sobre las consideraciones siguientes, además del ya expuesto método de decisión del contrato social rawlsiano, puede cfr. HOERSTER, Weinberger-FS (nota 74), pp. 233 ss., y especialmente BAURMANN, Strafe im Rechtstaat (nota 20), pp. 111, quienes, en términos similares a los aquí empleados, desarrollan esa perspectiva intersubjetiva en relación al tema que nos ocupa. Por otra parte, la concepción de Silva Sánchez, si bien es planteada desde otros términos, coincide sustancialmente, en este punto, con los presupuestos de un contrato social, tal y como él mismo destaca (SILVA SÁNCHEZ, Aproximación, p. 186). 
potenciales delincuentes, lo más racional sería en realidad la inexistencia de un Derecho penal, para evitar la limitación de sus intereses por parte del Estado; o, dado el presupuesto de la existencia de un ius puniendi, lo racional será en todo caso, la reducción al mínimo de su aspecto coactivo. Pero, tal y como expresa Rawls en su modelo de contrato social, presupuesto para la posibilidad de un diálogo y de arribar a un acuerdo sobre las instituciones que han de regir la convivencia pública es la facultad de lo razonable, la cual implica la tendencia a la cooperación basada en acuerdos que representaran los intereses de todos los implicados, cooperación que sólo puede realizarse por medio de sacrificar un ámbito de la libertad y los intereses propios en aras de un orden estable que garantice la libertad de todos. Y para establecer el marco de imparcialidad en la decisión, sabido es que en la posición original rawlsiana los coasociados deben decidir tras un velo de ignorancia, que, en aras de la imparcialidad en la decisión, oculta a los individuos la situación que de facto ocuparán en la sociedad ${ }^{107}$. Respecto al acuerdo sobre los fines y garantías en Derecho penal, ello conllevará que quienes toman parte en la decisión desconocerán, desde la "posición original”, si, una vez levantado el velo de ignorancia, serán potenciales delincuentes o ciudadanos respetuosos del Derecho. Por ello, todo participante en el pacto habrá de ponderar su decisión asumiendo que podría ser tanto víctima de acciones delictivas como verse sumido en el mecanismo coactivo del Derecho penal, por lo que lo racional de su decisión individual, es decir, la forma en que haya de obtener el mayor interés, habrá de estar regida por una ponderación de la racionalidad de ambos roles: el interés por una máxima prevención y el interés por un máximo de garantías ${ }^{108}$. De esta forma, lo razonable sería el establecimiento de un Derecho penal que sirviera tanto al fin de prevención de acciones lesivas por parte de terceras personas como al fin de protección de la libertad del ciudadano frente al poder coactivo del Estado. Dado el fin de protección preventiva, los ciudadanos acordarían el establecimiento de sanciones útiles en aras de ese fin, así como el sometimiento a la imposición de la sanción en caso de vulneración de las normas por todos consensuadas ${ }^{109}$. No obstante, para

${ }^{107}$ RAWLS, Teoría de la justicia (nota 10), pp. 29 y 165-166.

${ }^{108}$ En similar sentido, HOERSTER, Weinberger-FS (nota 74), p. 235; BAURMANN, Strafe im Rechtstaat (nota 20), pp. 115 ss.; SILVA SÁNCHEZ, Aproximación (nota 2), p. 186.

${ }^{109}$ A estos presupuestos liberales responde, por ejemplo, la "teoría consensual de la pena" desarrollada por Nino, con el fin de compatibilizar la fundamentación utilitarista con el respeto a los límites en la distribución de la pena propio de la retribución. Cfr. NINO, Introducción al análisis del Derecho (nota 13), pp. 431 ss; el mismo, Los límites de la responsabilidad penal, 1980, pp. 218 ss., cuyas premisas ya estaban, en cualquier caso, presentes en Feuerbach, influenciado por las concepciones kantianas (cfr. NEUMANN/SCHROTH, Neuere Theorien von Kriminalität und Strafe, 1980,, p. 35). 
llevar a cabo este fin, los ciudadanos acordarían entonces el establecimiento de unos principios garantísticos -culpabilidad, proporcionalidad, lesividad, etc.- a los cuales habría de acomodarse la labor del aparato coactivo para ser reconocido como un orden legítimo, y que no podrían ser instrumentalizados en aras de fines preventivos, puesto que ello vulneraría las condiciones de razonabilidad y ponderación de intereses contrapuestos en que se basa el acuerdo $^{110}$. Tal y como se dijo respecto de la relación entre la racionalidad instrumental y la racionalidad valorativa, ello implica que la prevención sólo podrá maximizarse dentro del ámbito de respeto a esos principios vinculantes para el Estado, en aras del fin que compete al mismo de satisfacción de ambas líneas de intereses, que en realidad no son otros que las que todo ciudadano racional interesado en su propia libertad tendría.

En suma, en un Derecho penal democrático "la misión del Derecho penal no consiste sólo en proteger bienes jurídicos...sino también en limitar el poder punitivo del Estado...trazando, a partir de principios generales de rango incluido constitucional, unas "reglas de juego" a las que todos, incluido el Estado, tienen que atenerse" $" 111$.

\section{La culpabilidad como reproche por un uso defectuoso de la libertad}

Hasta el momento, la culpabilidad ha venido siendo entendida como un principio limitador a la racionalidad preventiva. No obstante, la idea de la culpabilidad no debe entenderse sólo como límite, sino como fundamento de la sanción penal. Un orden social democrático, basado en la comunicación personal, no debe prescindir de la idea de la culpabilidad, por cuanto en el

\footnotetext{
${ }^{110}$ En relación a los criterios de autointerés racional bajo los que se llegaría a la fundamentación de dichos principios - sobre lo que no entraremos - puede cfr. BAURMANN, Folgenorientierung (nota 30), pp. 53 ss. (especialmente p. 62), quien viene a servirse de la regla maximin empleada por Rawls en su 'principio de la diferencia' ( cfr. RAWLS, Teoría de la justicia (nota 10), p. 97 ss. y 181 ss. ) - consistente, por decirlo así, en maximizar desde el mínimo: en optar por la alternativa cuyo peor resultado sea superior al peor resultado de las otras alternativas -, para fundamentar el principio de responsabilidad, entendiendo que "un Derecho penal sin principio de responsabilidad sólo sería legítimo cuando los más perjudicados por ese Derecho penal pudieran mejorar la suma de beneficio individual con la introducción de ese Derecho penal" ( p. 62), llegando, tras numerosas y complejas operaciones, a la conclusión de que los más perjudicados por ese Derecho penal - que serían los no responsables sometidos a castigo - verían de hecho disminuido su beneficio personal, por lo que sólo un Derecho penal con un principio de responsabilidad sería aceptado por todos. También, con menor complejidad y detalle, BAURMANN, Schuldlose Dogmatik? (nota 51), p. 255; NINO, Introducción al análisis del Derecho (nota 13), p. 432; HOERSTER, Weinberger-FS (nota 74), pp. 236 ss.; KINDHÄUSER, Personalität, Schuld und Vergeltung, GA 1989, p. 498; BAURMANN, Strafe im Rechtstaat (nota 20), pp. 131 ss.

${ }^{111}$ HASSEMER/MUÑOZ CONDE, Introducción (nota 104), p. 137.
} 
núcleo de su conformación teórica e ideológica se halla la idea de la responsabilidad personal, como correlato de la libertad individual.

Como ya hemos mencionado, lo característico de un orden social democrático es que está conformado a partir de la comunicación personal. Frente a la comunicación estratégica, que toma en consideración al otro de manera objetiva -esto es, como objeto de cálculo para la obtención de sus intereses de sus intereses-, la comunicación personal, en tanto orientada al acuerdo, asume al otro como un igual, en el que, por tanto, reconoce un mismo marco de competencia comunicativa y de autonomía, por cuanto sólo frente a un igual cabe establecer acuerdos ${ }^{112}$. En otras palabras, los ciudadanos no se interrelacionan desde el papel de meros observadores, sino desde el de participantes competentes en los procesos de intercambio social, capaces, entonces, de organizar racionalmente su propio ámbito de libertad y, por ello, de ser responsables acerca del uso de esa libertad ${ }^{113}$.

Ese mutuo reconocimiento de la autonomía comunicativa implica que las normas que regularán la convivencia serán fruto del acuerdo intersubjetivo, y que responderán, por tanto, a los intereses de todas las partes, por lo que los ciudadanos reconocerán en el orden jurídico un orden legítimo y vinculante ${ }^{114}$. Por ello, los ciudadanos se reconocen mutuamente como ciudadanos respetuosos de esas normas, en cuanto asumen que sólo el respeto generalizado de las mismas maximizará la estabilidad social y, con ello, su libertad $^{115}$. Asimismo, el Estado ha de contemplar a los destinatarios de las normas como personas responsables de organizar su libertad ${ }^{116}$ La vulneración de la norma constituye, entonces, una defraudación de las expectativas que todos tienen sobre los demás acerca de su respeto, pero esa defraudación sólo tiene lugar cuando ha sido realizada por quien es considerado como comunicativamente competente: sólo quien es reconocido como un igual, a efectos de la adscripción de esa competencia comunicativa, podrá ser considerado sujeto responsable por el uso defectuoso de su libertad, consistente en la vulneración del acuerdo intersubjetivo, porque sólo quien es considerado como igual ha sido sujeto de decisión en ese acuerdo.

En un orden social así conformado, la adscripción de culpabilidad conlleva un reproche o censura por lo realizado, reproche que, indudablemente,

\footnotetext{
${ }^{112}$ Cfr. HABERMAS, Teoría de la acción comunicativa (nota 95), pp. 136 ss.

${ }^{113}$ KUNZ, ZStW 98 (1986), p. 833-834; KINDHÄUSER, La culpa penal en un Estado democrático de Derecho (nota 99), p. 37-38; HÖRNLE/von HIRSCH, GA 1995, p. 267.

${ }^{114}$ Cfr., en este sentido, HABERMAS, Facticidad y validez, p. 578.

${ }^{115}$ KINDHÄUSER, La culpa penal en un Estado democrático de Derecho (nota 99), p. 43; ALCÁCER GUIRAO, Los fines del Derecho penal (nota 9), pp. 222 ss.

${ }^{116}$ HÖRNLE/von HIRSCH, GA 1995, p. 267.
} 
incorpora un juicio de desvalor ${ }^{117}$; pero esa censura desvalorativa sólo puede imputarse a quien es reconocido como responsable de la organización de su autonomía, a quien, en otros términos, es considerado como comunicativamente competente ${ }^{118}$. Esa conclusión, además, se corresponde con nuestra intuiciones morales cuando asignamos responsabilidad, tal y como ha mostrado Strawson ${ }^{119}$. Afirma este autor que en nuestras relaciones intepersonales podemos ostentar frente al otro dos clases de actitudes: una actitud participativa y una actitud objetiva. La actitud objetiva consiste en asumirlo "como un objeto de táctica social, como sujeto a lo que, en un sentido muy amplio, cabe llamar tratamiento", como alguien, en suma, con quien no puede dialogarse, por no ser considerado como un igual en las relaciones de intercambio social y, por ello, frente a quien no cabe reaccionar con actitudes morales, por cuanto no se pueden albergar expectativas morales de conducta $^{120}$. Es sólo con quienes mantenemos una actitud participativa con quienes podemos establecer un diálogo, requisito para lo cual es - como ya vimos con la comunicación personal - reconocer en el otro una situación de igualdad y libertad, y frente a quienes mantenemos actitudes reactivas de reproche y censura, porque sólo con quienes mantenemos esa actitud dialógica es a quienes atribuimos responsabilidad ${ }^{121}$. El presupuesto de que la responsabilidad sólo puede atribuirse a quien consideramos capaz de establecer una comunicación personal como un igual yace ya en la misma etimología del término: respondere; responsable es aquel que puede responder de sus actos, de justificarlo con razones -y no con excusas-. En el intercambio social, partimos de una actitud participativa con el resto, pero puede haber casos en los que la situación nos lleve a modificar esa actitud y a adoptar una actitud objetiva: situaciones en las cuales quien ha realizado una acción contraria a una norma se halla en una situación de desigualdad de cara a atender el mensaje comunicativo que la norma expresa -básicamente por defectos psíquicos-; dichos casos, afirma Strawson, "invitan a suspender nuestras actitudes reactivas habituales hacia el agente (...) No nos invitan a ver la acción del agente de un modo que sea consistente con la plena retención de

\footnotetext{
${ }^{117}$ KUNZ, ZStW 98 (1986), p. 835-836; HÖRNLE/von HIRSCH, GA 1995, pp. 270 ss.

${ }^{118}$ Como afirman HÖRNLE/von HIRSCH, GA 1995, p. 272, “el fundamento para la atribución de ese desvalor radica en el reconocimiento de la persona como agente con capacidad de autodeterminación moral".

${ }^{119}$ Ello es citado en similar sentido también por BURKHARDT, Charaktermangel und Charakterschuld (nota 71), pp. 118 ss.

${ }^{120}$ STRAWSON, Libertad y resentimiento, en: Strawson, Libertad y resentimiento, 1995 , pp. $46 \mathrm{~s}$.

${ }^{121}$ Así, BURKHARDT, Charaktermangel und Charakterschuld (nota 71), p. 119, citando a Habermas.
} 
las actitudes interpersonales habituales y meramente inconsistente con una actitud particular. Invitan a ver al agente mismo bajo una luz diferente de aquella a la que normalmente veríamos a quien ha actuado como él lo ha hecho" "122. Todo ello puede resumirse con los términos de Jakobs: el inimputable no profiere comunicación con sentido penalmente relevante, por lo que su acción es considerada como naturaleza: objetivamente ${ }^{123}$.

Desde esos presupuestos, puede concluirse que para determinar la culpabilidad no puede atenderse sólo al parámetro de la necesidad social de reafirmación de la vigencia de las normas, porque estaríamos acogiendo una actitud meramente objetiva con respecto a quien se impone la pena ${ }^{124}$, sino que la atribución de responsabilidad debe partir de, por decirlo así, las condiciones que permiten la interacción comunicativa, esto es, los factores individuales que permiten atribuir esa competencia y establecer el marco de igualdad frente a las posibilidades de acceso al mensaje normativo ${ }^{125}$.

Todo ello no implica negar carácter funcional a la culpabilidad, si bien no en el mismo sentido que se entiende por parte de la doctrina. Pueden encontrarse dos razones para asignar a la culpabilidad como un elemento funcional a los fines de estabilidad de las normas jurídicas en la sociedad.

En primer lugar, porque la atribución de responsabilidad sólo ha de establecerse cuando ello es necesario. Así, la concepción funcional de la culpabilidad puede admitirse en su sentido negativo: nulla culpa sine necessitate. Si no es necesaria una redacción ante un hecho - por cuanto no posee carácter desestabilizador- no será preciso asignar responsabilidad. Ahora

${ }^{122}$ STRAWSON, Libertad y resentimiento (nota 121), pp. 45-46. El mismo JAKOBS, Sobre el tratamiento de los defectos volitivos y de los defectos cognitivos, en: Jakobs, Estudios de Derecho penal, 1997, p. 130, parte de muy similares presupuestos, cuando sostiene que frente a inimputables "no resulta necesaria respuesta alguna cuando la toma de posición proviene de una instancia que no es competente para interpretar las normas de convivencia (...) Se hace así referencia a personas cuya conducta puede ser explicada sólo a través de un parámetro objetivo, y en las que la falta de modulación de dicho parámetro también está condicionada objetivamente".

${ }^{123}$ Vid., en similar sentido, desde una perspectiva ética, BRIESKORN, Verantwortungsstrukturen in sozialethischer Sicht, en: Neumann/Schulz (editores), Verantwortung in Recht und Moral, ARSP número especial 74, 2000, p. 199: la consideración de alguien como mero causante de una acción y no como responsable, implica tomarle como mero elemento de la naturaleza y no como ser libre.

${ }^{124}$ BURKHARDT, Charaktermangel und Charakterschuld (nota 71), p. 121.

${ }^{125}$ Afirma, así, KINDHÄUSER, La culpa penal en un Estado democrático de Derecho (nota 99), p. 29, nota 26: "para el anclamiento de la culpa en la "comunicación personal", la cual se basa en relaciones recíprocas de reconocimiento, no se pueden combinar ni una consideración funcional puramente externa del concepto de culpa, ni la desatención de los constituyentes psíquicos al concepto de persona". 
bien, ello no permite su formulación en sentido positivo, entendiendo que siempre que sea necesaria la pena habrá de imputarse responsabilidad.

En segundo lugar, porque, como un argumento derivado del principio democrático y de la autonomía política del ciudadano, sólo la imposición de una pena de acuerdo con las exigencias de justicia intersubjetivamente reconocidas conllevará la aceptación del ordenamiento como un orden justo. Ahora bien, como ya afirmamos con anterioridad, ello no debe entenderse como la producción coyuntural de u consenso en virtud de la consecución de las necesidades de castigo de la oblación. En otras palabras, la afirmación de que "sólo la pena justa será una pena útil" no significa lo mismo que la afirmación de que "sólo una pena útil será una pena justa". La primera es un postulado del ámbito de la legitimidad, en la que la variable principal es la de la justicia; la segunda es un postulado basado exclusivamente en la estabilidad, en el que la variable esencial es la utilidad. Y ambos planos no deben confundirse: la prevención siempre estará al servicio de la justicia, y no la justicia al servicio de la prevención ${ }^{126}$.

En conclusión, la culpabilidad no puede configurarse exclusivamente desde la prevención, sino que ha de responder siempre a una ponderación sintética de las dos direcciones enfrentadas: necesidad preventiva y garantía individual limitadora ${ }^{127}$.

${ }^{126}$ En sentido similar, NEUMANN, Neue entwicklungen im Bereich der Argumentationsmuster zur Begründung oder zum Ausschluss strafrechtlicher Verantwortlichkeit, ZStW 99 (1987), p. 592.

${ }^{127}$ En sentido similar, SILVA SÁNCHEZ, Aproximación (nota 2), pp. 393 ss. 
$\triangle \quad$ DOXA 25 (2002) 